\title{
Ethnic segregation and native out-migration in Copenhagen
}

Marcin Stonawski, Cracow University of Economics

Adrian Farner Rogne, University of Oslo

Henning Christiansen, Statistics Denmark

Henrik Bang, Statistics Denmark

Torkild Hovde Lyngstad*, University of Oslo

*Corresponding author: T.H.Lyngstad, Dept of Socoiology and Human Geography, University of Oslo, 0317 OSLO Norway. E-mail: torkild.lyngstad@gmail.com.

\begin{abstract}
We study how the local concentration of ethnic minorities relates to natives' likelihood of outmigration in the capital of Denmark. In US studies, a high or increasing proportion of racial or ethnic minorities in inner city neighborhoods is seen as the prime motivation for 'white flight;' White middle-class families moving towards racially and ethnically homogeneous suburbs. The relatively egalitarian Scandinavian setting offers a contrasting case, where inner cities are less deprived, and where minority groups primarily consist of immigrants and children of immigrants that have arrived over the past few decades. Using rich, population-wide, longitudinal administrative data over a twelve-year period, linked to exact coordinates on places of residence, we document how the geographical distribution of minorities within Copenhagen relates to native out-migration. We observe increasing out-migration among the native majority population from areas with high and increasing minority concentrations, largely supporting the hypothesis of a 'native flight' mobility pattern.
\end{abstract}

Keywords: mobility, segregation, diversity, neighborhoods, register data.

Acknowledgements: The authors acknowledge funding from the Research Council of Norway grant \#241357.

Conflicts of interests: None. 


\section{Introduction}

In most diverse societies, residential segregation along racial or ethnic lines is a salient issue. The composition of the local population and the relative concentration of minority and majority groups has been hypothesized to affect individuals' day-to-day interaction patterns (Moody 2001), risk of poverty (Massey et al. 1987), children's school achievements (Jensen and Würtz 2011), and a host of other social and economic outcomes.

Residential segregation can emerge as a result of several different processes. One contributing factor is when the residential choices of majority and minority groups are motivated in part by preferences regarding neighbourhoods' racial or ethnic composition. In the United States, the hypothesis of 'white flight' has long been part of the discussion of continued residential segregation by race. Coined to describe the suburbanization of white families, a pattern of migration of relatively affluent whites from racially mixed inner cities to racially homogeneous suburbs, which contributed to the emergence of inner city areas consisting largely of marginalized African-Americans (Crowder 2000; Crowder and South 2008; Crodwer et al. 2009)

In this article, we study whether the local concentrations of ethnic minorities in the Copenhagen metropolitan area affect natives' out-migration patterns from such neighbourhoods. We draw on longitudinal geocoded coordinate data linked to large-scale population-wide administrative register data on the complete population of the Copenhagen metropolitan area. This allows us to use individuals' places of residence to form individualized scalable neighbourhoods to define social surroundings.

Denmark has a relatively short history of large-scale international migration, with modern labour migrants arriving first in the 1960s. The immigrant population has grown rapidly since then, and now includes large groups of migrants who are visibly and culturally distinguishable from the majority population. Integration of ethnic minorities in Denmark has been a topic of much research and public debate. While there is evidence of relatively weak socioeconomic assimilation among the first generation of immigrants to Scandinavian countries, and particularly among refugees and immigrants from non-OECD-countries (see e.g. Husted et al. 2001; Longva and Raaum 2003; Galloway and Aaberge 2005), their descendants seem to some extent have become an economic success story (Hermansen 2013). To the extent that social ties to the native population mediated through neighbourhoods serves as a resource for integration, patterns of native out-migration and increased residential segregation may undermine further integration of minorities. 


\section{The Copenhagen context and its migrant population}

The population size of the greater Copenhagen area increased from 1.21 to 1.33 million inhabitants between 1980 and 2019. Over the same period, the share of immigrants and their descendants increased from $6.3 \%$ to $22.9 \%$ of the population, with the share of descendants increasing markedly sharper than the share of immigrants.

The composition of the immigrant origin population also changed significantly in the period 1980-2019. Table 1 shows the population sizes of the 20 largest immigrant groups and changes in these groups from 1980 to 2019. In Copenhagen in 1980, the share of the immigrant population coming from Western countries (defined as the current European Union/EFTA members, USA, Canada, Australia and New Zealand) was around 60\%, and approximately half of these originated from neighbouring countries. In 2019 the percentage of residents from Western immigrant origins was lower, and people from neighbouring Sweden, Germany and Norway made up only $8 \%$ of the immigrant origin population. The diversity of the immigrant origin population increased in the period: In 1980 the twenty biggest country of origin groups made up $82.6 \%$ of the immigrant origin population, while in 2019 the corresponding share was just $66.1 \%$. The largest groups in the immigrant origin population of Copenhagen in 2019 were from Turkey (31.3 thousand), Pakistan (21.6), Iraq (13.6), Poland (12.4) and Germany (9.5).

The current composition of the immigrant origin population in the Copenhagen area was shaped by migration flows starting around the second half of the 1960s, when workers from Turkey, Pakistan, former Yugoslavia and Morocco arrived by way of the so-called workforce-immigration program. During the 1980s and 1990s, migration streams originated from conflict regions (Iran, Iraq, Lebanon, Somalia and Bosnia and Herzegovina). The 2000s were dominated by flows of asylum seekers from various origins and immigrants from Eastern Europe, who, following the enlargement of the European Union, had access to the Danish labour market. In 2019, people of Polish origin ranked the fourth largest immigrant group in the city.

Housing policies and housing prices, migration inflows and labour market developments have contributed to segregation processes and outcomes in Copenhagen. It is worth noting that Denmark has historically led an extensive policy aimed at providing affordable housing for all residents through means such as tax deductions for mortgage interests and direct subsidies for rented housing, as well as rent regulation (Kristensen 2002). Approximately half of Danish residential units are owner-occupied. The proportion of owner- 
occupied units is far lower in the Copenhagen area, where approximately two in five and one in five residences are owner occupied in the regions 'Københavns omegn' and 'Byen København', respectively (Statistics Denmark n.a.). For many immigrants in the urban areas, social housing and dwellings in disadvantaged neighbourhoods have been the most easily available housing options (Kristensen 2002), resulting in political concerns over concentrations of social problems in such areas (Ministry of Refugees, Immigration and Integration Affairs 2004). Following the 2001 election, the Ministry of Housing was closed down and its activities were transferred to several other ministries, as the national government took a less active role in housing policy.

The issue of of residential segregation is a major political factor in Denmark. Its salience stems from its link to larger, integration-related issues. The country's immigration policy have the last decade stood out as being markedly stricter than those of neighboring countries. Denmark has also had a more intense public debate about immigration and integration (Green-Pedersen and Krogstrup 2008).

\section{Theoretical perspectives and research on segregation and flight}

As mentioned, the concept 'white flight' was coined in the US, and is used to describe a process whereby white middle class families move from the central cities to suburbs within US metropolitan areas (e.g. South and Crowder 1997; Massey et al. 1994, Crowder and South 2008). The main assumption is that white households residing in mixed neighbourhoods tend to move out of such neighbourhoods because of the high or increasing minority share of the neighbourhood population. As predicted by the Schelling (1971) model, such a process may be driven by Whites' preferences for a certain proportion of own-group members in their neighbourhood. This argument is supported by a comprehensive literature showing that owngroup preferences exist among both majority and minority populations, though several studies find that some minority populations tend to prefer integrated neighbourhoods (Emerson et al. 2001; van Ham and Feijten 2008; Krysan et al. 2009; Clark 2002; Clark and Coulter 2015). Further, studies building on, expanding and modifying the Schelling model have shown that such preferences are capable of explaining persisting patterns of segregation through selective moving behaviour (see for instance Fossett 2006; Clark and Fossett 2008; Aldén et al. 2015), though the model has also received criticism (Bruch and Mare 2006). Other studies suggests that stereotypes, prejudice and negative attitudes towards other races, ethnicities and 
immigrants are the causes of out-migration (Farley et al. 1994; 1997; Krysan 2002; Wilson and Taub 2006), rather than mundane preferences.

However, a number of factors unrelated to the racial or ethnic composition of neighbourhoods may also produce similar patterns. For instance, immigrants may settle in areas where the resident natives are generally more mobile (Crowder et al. 2011). According to the socioeconomic context thesis, conditions of the neighbourhood are more important predictors of out-migration than ethnicity (or race) per se. An increase in the concentration of minority groups in an area may be associated with, or even generated by, a worsening of the socioeconomic conditions in that area. For instance, deterioration of the quality of education, poorer employment prospects, and an increase in crime may affect the neighbourhood composition through several mechanisms (Rathelot and Safi 2014; Crowder et al. 2011; Betts and Fairlie 2001), including shifts in housing prices allowing relatively poor minority groups to settle. This transformation of neighbourhoods in turn may become a push factor for migration decisions. However, as Goodwin-White (2018) shows, the impact of a neighbourhood may be conditional on the characteristics of movers and stayers; people who may benefit from moving are more likely to do so, meaning that selection processes may be important. In a similar vein, the racial proxy hypothesis suggests that an influx of minorities in a neighbourhood is a signal of socioeconomic deprivation, and that this is what motivates the moving behaviour of the majority population (Clark and Coulter 2015). The housing competition model, on the other hand, suggests that an influx of minorities can increase prices and increase the cost of renting which can stimulate socioeconomically lower situated majority group members to leave the neighbourhood (Crowder et al. 2011; Ley and Tutchener 2001). A different argument is provided by the labour market competition hypothesis, which suggests that an influx and an increasing concentration of minorities, particularly migrants, increases competition in the local labour market. A potential response to this pressure is for the population groups already in place to migrate out of the area (Borjas 2006; Frey 1995; 1996; Filer 1992). Moreover, micro-level characteristics (individual and household) are important intervening factors in the relationship between out-migration and the local concentration of minorities. For example, there may be differences in the probabilities of out-migration by age, sex, marital status, number of children, and household income (Crowder 2000; Sabater and Finney 2014). Additionally, the notion that high ethnic minority concentrations are somehow problematic, or are perceived as problematic by movers, should be accompanied by an important caveat; ethnic segregation may in some instances yield benefits to newly arrived immigrants. Ethnic enclaves may provide social networks, support and employment 
opportunities, as well as a sense of cultural and lingual community for ethnic minorities (Wilson and Portes, 1980; French 2014; Edin et al. 2003; Musterd and van Gent 2012).

Regardless of the exact mechanism producing these moving patterns, several studies have shown robust patterns of white or native flight even after control for numerous relevant individual- and neighbourhood-level characteristics (see for instance Crowder et al. 2011; Crowder et al. 2012; Bolt et al. 2008; Andersen 2017).

The bulk of the literature on white or native flight stems from the United States. US studies usually distinguish between different races, such as Blacks, Whites and Hispanics, and studies show that the phenomenon of 'flight' is not solely related to the Caucasian population. Similar patterns can be observed among African-American inhabitants in the US (Crowder et al. 2012, Pais et al. 2009, Woldoff 2011, South and Crowder 1998). For example, Crowder et al. (2012) indicate that the probability of out-migration is significantly associated with racial composition of the origin neighbourhood, both for whites and blacks, controlling for other socioeconomic characteristics of the individual and the neighbourhood. Pais et al. (2009) document a type of out-migration that they call 'minority flight' in cases where the probability of out-migration increases for minorities (e.g. Latinos) in white dominated neighbourhoods because of, for example, real or perceived discrimination. Several studies show that the flight thesis can be extended beyond racial segregation and be applied to the mobility of the native and immigrant origin population in the US. For instance, Crowder et al. (2011) observe intensified out-migration among natives (Whites and Blacks) when the share of immigrants increases in a neighbourhood. Similarly, studying migration patterns related to the labour market, Borjas (2006) finds that native out-migration increases with immigration-induced increases in the supply of labour. Hall and Crowder (2014) add that the association between the out-migration of natives (Whites and Blacks) and the concentration of immigrants is significantly more pronounced in developing gateways of migration than in developed ones.

Above and beyond the current composition of neighbourhoods, Bråmå (2006) suggests that the rate of the change in composition may be important for out-migration. Moreover, Crowder et al. (2011) suggest that immigrant concentration in the surrounding areas likely also has an effect on out-migration, by constraining the opportunities of finding nearby neighbourhoods with more ethnically homogeneous populations.

\subsection{Out-migration, flight and avoidance in Europe}

Concerns over the integration of immigrants from non-Western countries and their concentration in relatively disadvantaged urban areas has generated increasing interest in 
residential segregation among social scientists in Europe. However, in European settings, and particularly in the Nordic countries, the notion of 'white flight' as discussed in the American literature may be less relevant. Segregation is here often conceptualized as the separation of the native or ethnic majority population from immigrant or other ethnic minority populations, rather than the separation of different racial groups. The relatively short history of large-scale immigration makes the comparison with the US difficult, given the long US history of racial oppression and discrimination, particularly of the African American population. Another important difference is the existence of more extensive welfare states, which may attenuate socioeconomic neighbourhood deprivation. Notably, inner cities are generally less deprived in European countries than in the US, and even less so in Scandinavia. Despite these differences, however, it is reasonable to assume that some of the mechanisms that produce white flight in the American context may work similarly to produce a native flight in Denmark and other European contexts. Particularly, one might expect the dynamics of in-group/out-group preferences to translate into preferences for native/minority compositions of neighbourhoods, producing patterns of native flight from neighbourhoods with high and growing proportions of minorities. However, studies of white flight or native flight in European contexts have so far shown mixed results.

Based on a study of four big cities in Netherlands, Bolt et al. (2008) provide evidence that Dutch and Western immigrants have a higher probability than non-Western migrants to move out of neighbourhoods with high concentrations of immigrants. The natives also tend to migrate to areas with lower proportions of minorities. Van Ham and Feijten (2008) also show that, with increases in the immigrant population, Dutch natives tend to more strongly wish to leave their neighbourhoods. A similar study by Clark and Coulter (2015) found neighbourhood deprivation, changes in the neighbourhood ethnic composition, and changes in housing tenure distribution to be associated with preferences for moving, and that feeling similar to others and the feeling of belonging in a neighbourhood was associated with a lower desire to move. However, they found individual characteristics to matter more than neighbourhood characteristics. In France, Rathelot and Safi (2014) showed that the probability of outmigration from Parisian neighbourhoods with a high share of immigrants is higher for natives. However, this effect becomes small and insignificant once all fixed characteristics of the geographic area are introduced into the regression models. Similarly, Simpson and Finney (2009), using census data, did not find evidence of a native flight pattern in Britain. They suggest that out-migration can be explained by aspirations to improve living conditions that are shared by all ethnic groups. Bråmå $(2006,2008)$ provides evidence to reject the hypothesis 
that the "flight" of Swedes caused further ethnic segregation and immigrant concentration in Swedish cites, and argues that the main cause of increasing segregation is avoidance-like behaviour of natives, i.e. natives avoid moving into areas with high proportions of minorities, rather than move out of them. Andersson (2013) confirmed that Stockholm residents tend to avoid multi-ethnic neighbourhoods, but found no evidence for the 'white flight' hypothesis. There is evidence for native out-migration as a response to high concentrations of minorities in urban areas of Sweden (Aldén et al. 2015), Norway (Wessel and Nordvik 2019), and France (McAvay 2018).

In an anthology edited by Lloyd, Shuttleworth and Wong (2014), several authors shed some additional light on residential mobility processes and how these may contribute to residential segregation. For instance, Shuttleworth et al. (2014) show that among Protestants and Catholics in Northern Ireland, selective moves corresponded with patterns of out-migration and flight from neighbourhoods with high shares of out-group members. However, this did not translate into increasing segregation, because, in addition to the effects of births and deaths, most moves were short distances between similar neighbourhoods, and relatively few lived in neighbourhoods dominated by their out-group. Van Ham and Manley (2014) show that social housing market policies in England affect residential sorting between minority and majority groups in a manner consistent with the notion of selective moves, leading minority groups to move into deprived neighbourhoods. In a related vein, but returning to the US context, Hwang (2014) shows how the housing market in St Louis and Cincinnati contributes to racial segregation.

In the case of Denmark, the literature focusing on flight is scant. Ethnic minorities in Denmark often live in less attractive areas with more social problems. The city of Copenhagen is experiencing an increase in spatial segregation in housing and education (Møller and Larsen 2015). Moreover, in the period 2000-2008 non-Western immigrants in Copenhagen did not improve their neighbourhood status, whereas the native group did, according to a study of spatial integration of immigrants in Nordic cities (Wessel et al. 2016). Andersen (2017) presents a study of residential mobility in Denmark in 1985-2008 using data on non-Western immigrants aged 15 or older and a sample of Danes from administrative registers. Based on information on 9.000 neighbourhoods (approximately 600 inhabitants each), he used a logistic regression model of out-migration with control characteristics (individual, household and neighbourhood). The study provides some evidence of native flight in Denmark, as the probability of out-migration increases with the share of immigrants. But native avoidance seems more important than native flight in producing spatial segregation patterns. 


\subsection{Our contribution, hypotheses, and expectations}

This article contributes to the literature in several ways. First, we offer a longitudinal view of native out-migration, where we relate neighbourhood characteristics and changes in neighbourhood characteristics to the likelihood of an individual's out-migration. We use individualized scalable neighbourhoods based on high-quality register data with detailed geographical coordinates on all residents of the Copenhagen metropolitan area. This allows us to circumvent the problem of aggregation, an important part of the modifiable areal unit problem (MAUP, see Nielsen and Hennerdal 2017). Second, we address several different aspects of the dynamics of residential segregation, including the importance of the extralocal neighbourhood composition and majority/minority group differences in moving patterns. Third, we study not only out-migration for the whole population, but also analyse whether the sensitivity to the local neighbourhood composition and changes in this composition is different for individuals with and without own children, assess the robustness of our estimates to different specifications of the minority group, and provide a discussion of the distinction between out-migration and flight.

Based on the brief overview of the literature reviewed above, we set out several hypotheses on how native out-migration choices are associated with the ethnic composition and changes in the ethnic composition of the neighbourhood. First, we set out to test the native out-migration hypothesis:

1) The likelihood of native out-migration is higher when the share of minorities is higher, and it increases when the share of minorities increases.

Second, we also posit what we call the stronger native out-migration hypothesis, emphasizing that the native out-migration phenomenon is not exclusively about neighbourhood characteristics, and that the importance of the proportion of minorities in the neighbourhood should depend heavily on whether or not oneself is a member of a minority group:

2) The probability of moving out of neighbourhoods with high concentrations of minorities is markedly higher among natives than among descendants of immigrants.

We also want to examine the hypothesis that the concentration of minorities in the extralocal area, the larger area beyond the immediate neighbourhood, is negatively associated 
with out-migration decisions in the native population. According to Crowder et al. (2011) an increase in the extralocal concentration of minorities, may lead to a reduction in the probability of moving out for the majority group. The reason for this is that for structural reasons (e.g. commuting patterns and family ties) most migrations take place over rather short distances, and an increase in the concentration of minorities in the extralocal area limits the migration options for individuals whose tolerance for minority groups is low. Thus, our third hypothesis, the extralocal opportunities hypothesis states:

3) A higher concentration of minorities in the extralocal area is negatively associated with native out-migration.

Finally, we also study whether having children moderates individuals' sensitivity to local conditions. Our fourth hypothesis is thus:

4) The response to the concentration of minorities and changes in the concentration of minorities is weaker among childless natives than among native parents.

Having own children likely increases one's response to local conditions that otherwise would not be given much weight, such as children's school environments and environments for language learning. Such factors could increase the sensitivity to the local population composition for those with children, but likely not among the childless.

\section{Data and Methods}

For our empirical analysis, we use data from the administrative population registers of Denmark, administered by Statistics Denmark. Our data consist of individual and neighbourhood characteristics for the urban area of Copenhagen in 2007, 2011 and 2014. In addition, we use data from 2003 to calculate changes in neighbourhood characteristics in the period from 2003 to 2007. The urban agglomeration area in and around Copenhagen is defined as two NUTS-3 areas: 'Byen København' and 'Københavns omegn' which in total consist of 17 municipalities: København, Frederiksberg, Dragør, Tårnby, Albertslund, Ballerup, Brøndby, Gentofte, Gladsaxe, Glostrup, Herlev, Hvidovre, Høje-Taastrup, Ishøj, Lyngby-Taarbæk, Rødovre and Vallensbæk. In 2014, this area had 1.26 million inhabitants and has grown by 
around 106 thousand since 2007. Our data include all individuals who were registered as resident in these areas in any of these calendar years. Our data include individual-level characteristics for all these individuals (cf. section 4.2), which importantly include the geographical coordinates of the individual's place of residence. The individual-level data were then complemented with characteristics of each individual's neighbourhood.

\subsection{Defining the Neighbourhood: the individualized approach}

A key challenge to all research on neighbourhoods and aspects of their composition is how to define the size of the neighbourhood (Damm and Schultz-Nielsen 2008). Most of the research on segregation and mobility patterns use some kind of prior definition of neighbourhoods, usually city districts or census tracts which typically are defined by historical borders, by roads or natural obstacles (such as rivers dividing cities), or for other practical, administrative or political purposes. Such neighbourhood definitions mean that the borders may be somewhat arbitrarily defined, however, and they may be at odds with the actual, spatial patterns of social interactions. Local neighbourhoods do not necessarily stop at administrative borders, and segregation patterns may not follow the structure of the administrative units.

Individualized scalable neighbourhoods, on the other hand, are neighbourhoods defined by the individual's location, where each individual's neighbourhood is defined as their $k$ nearest neighbours (Östh, Malmberg, and Andersson 2014; Östh, Clark, and Malmberg 2015). The basic premise of the individualized approach is to calculate statistics over these $k$ individuals (or households). Thus, in this approach, the neighbourhood is defined around individuals rather than being based on the borders of the administrative unit the individual resides in. Our data on place of residence measure location down to a 100x100m grid. This access to detailed geographical coordinates of residency for all individuals in the population thus makes it possible to measure neighbourhood characteristics in a much more flexible way than most previous studies. In our calculations of neighbourhood characteristics, we used the specialized software EquiPop, developed by population geographer John Östh (2013).

\subsection{Analysis variables}

This main dependent variable is an indicator of whether an individual changed a place of living during a calendar year. We measure this change by comparing grid cells where an individual lived at the beginning (January 1st) and at the end of year $t$ (December $31 \mathrm{st}$ ). If the codes of the two grid cells are different, we denote this situation as an 'out-migration' event. In a separate analysis, described below, we also use an alternative definition, where a move is 
counted only when the destination has a lower concentration of minorities than the origin. Individuals that died or emigrated during a year, or have missing addresses, are excluded from the analysis.

Mobility and segregation patterns are highly structured along demographic and socioeconomic dimensions. Minority populations may for example be younger and more maledominated than majority populations. To avoid confusing effects of the environment with effects of individual characteristics, we include six individual-level control variables in order to improve comparability of individuals living in different neighbourhoods: Age is represented by a set of dummy variables indicating three broad age groups; 25-44, 45-64 and 65 or more years, sex as a dummy variable showing if a person is a male, marital status which indicates if an individual does not live in a registered form of partnership, and number of children defined as a categorical variable with levels Childless, 1-2 or 3+ children. Educational attainment is defined as a categorical variable with levels primary or lower secondary (low), higher secondary (medium) or tertiary level (high) education. The variable "Labour market" is a dummy variable indicating whether the person is currently in the labour force or not. Finally, we also include dummy variables for year to capture any secular trends in mobility.

A particular interest is to explore variation in moving patterns between people with different origins. We construct a variable indicating any immigrant origin using information on the individual's country of birth and one's own and parents' immigration status (native, immigrant, and descendant). Importantly, according to the definition by Statistics Denmark, 'descendants' are only those where neither parent had a Danish citizenship before the birth of the child. If at least one of the parents was naturalized before the birth of the child, then the child is treated as a native Dane. Thus, descendants are presumably individuals whose parents were relatively less integrated in Danish society than naturalized immigrants were.

In this article, we primarily wish to investigate whether native Danes move out of neighbourhoods with high concentrations of minorities. But defining the minority group based on register data is not trivial and involves some difficult choices. We do not know which characteristics of minorities are most salient, and have limited data on potentially relevant traits. On the one hand, visual or phenotypical traits such as skin colour may be important, as individuals with visible traits distinguishing them from the majority population may be subject to prejudice, discrimination, racialization, avoidance etc. from the majority population. On the other hand, recent media debates and evident prejudice and hostility towards Muslims suggest that Muslim minorities may be particularly subject to negative stereotypes. Additionally, research on ethnic segregation in Europe commonly focuses on divisions between people from 
Western and non-Western origins (however defined), in part due to some notion of cultural proximity, and in part due to the different reasons for migration that have historically been important for different country of origin groups. Notably, refugees, asylum seekers and their families mostly originate from non-Western countries, while immigrants from Western countries more commonly arrive as labour migrants, particularly after the EU expansion in 2004, or as students. Other options include grouping all immigrants and descendants, regardless of country of origin, or distinguishing between European and non-European backgrounds. Danish register data contain information on immigration background and country of origin, but not on other potentially salient traits such as skin colour, 'race', religious affiliation etc. Thus, groupings based on such characteristics have to be proxied by country of origin, though we acknowledge that this approach is far from ideal. In this article, we use three different groupings, based on the notion of 'visible minorities', 'non-Western' country of origin, and 'predominantly Muslim' country of origin.

For the 'visible minority' grouping, we categorize individuals as belonging to the minority group if they originate (i.e. are immigrants or descendants of immigrants) from countries outside of Europe (excl. Turkey), North America and Oceania, as these groups are likely to have phenotypical traits that distinguish them from the majority population in Denmark. In the second grouping, by 'Western' versus 'non-Western' origin, we use a similar grouping, but also include individuals from non-EU/EFTA countries in Europe, and Oceania except Australia and New Zealand in the minority group. In the third grouping, we distinguish based on the majority religion of the country of origin, defining the minority group as immigrants and descendants of immigrants from a 'predominantly Muslim' country. We define predominantly Muslim countries as countries where at least $80 \%$ of the population identify as Muslims (in total 37 countries), according to the religious composition estimates of Pew Research Center (2012). These groupings are used to construct the neighbourhood level characteristics used.

To some extent, the choice of grouping is arbitrary, and we have no strong assumptions about what groups or traits are most salient. We have opted to use the grouping based on the 'visible minority' concept in our main analysis, but present the main results from analyses where we distinguish minorities from predominantly Muslim countries of origin and from nonWestern countries in the supplementary materials (S6.1).

We measure both the local concentration of minorities (immigrants and descendants of immigrants in the minority group), change in the local concentration of minorities, and, following Crowder et al. (2011), the concentration of minorities in the extralocal 
neighbourhood. The local concentration of minorities is measured as the share of minority individuals in the focal individual's egocentric neighbourhood consisting of $k=800$ individuals. The change in the local concentration of minorities is measured as the change in this concentration between years under consideration (2007 vs. 2003, 2011 vs. 2007, 2014 vs. 2011). The concentration of minorities in the extralocal neighbourhood is measured as the share of minorities among the 51200 nearest neighbours. We also tap into socioeconomic characteristics of the neighbourhoods by including the neighbourhood's educational level, measured by share of individuals aged 25-64 that have completed tertiary education, and neighbourhood affluence, measured as the share of people aged 25-64 who have a level of taxable income in the highest decile of the national income distribution. Descriptive statistics are listed in in Tables 1 and 2.

\subsection{Model specifications}

We estimate several logistic regression models for the individual decision to leave one's neighbourhood during a year. The right-hand-side of Model 1 include the concentration of minorities, change in this concentration from the previous period, as well as a control for the concentration of minorities in the extralocal area. Then, we add controls for other characteristics of the neighbourhood (Model 2). Finally, we include individual-level controls (Model 3). This set of models is estimated on the full population of natives and descendants, and then separately for natives and descendants. In all models, we correct for the nonindependence of observations using a clustering procedure to calculate robust standard errors.

We also include supplementary analyses (S6.1 and S4.1-S4.3) where we explore to what extent our results are dependent on the definition of the minority group, and assess patterns of 'flight' (defined as moves to neighbourhoods with lower minority concentrations) as opposed to 'out-migration' (moves to any other neighbourhood).

\section{Results}

\subsection{The link between ethnic composition and out-mobility}

Table 4 reports the results from our set of models estimated on the full population; natives and descendants of immigrants. The findings suggest that the likelihood of moving out of a neighbourhood is higher if the share of minorities in the neighbourhood is high. A one standard 
deviation higher share of minorities is associated with approximately a $9 \%$ increase in the odds of out-migration $(s d=0.10, b=0.912)$ when controlling for individual and neighbourhood characteristics (Model 3). It is also clear that a an increase over time in the share of minorities in the neighbourhood population is also positively associated with out-migration when other characteristics are controlled for (including the level of the minority concentration). An increase in the proportion of minorities of one standard deviation is associated with an approximately $3 \%$ higher odds of out-migration. The concentration of minorities in the extralocal area is negatively and statistically significantly associated with out-migration. This association is, however, somewhat weaker than the association with the proportion of minorities in the local neighbourhood $(k=800)$. Thus, net of the diversity of one's larger city district, the diversity of one's neighbourhood seems to matter for migration decisions.

As mentioned above, it is reasonable to assume that the socioeconomic profile of a neighbourhood may confound the relationship between minority representation and outmigration. We have therefore controlled for two indicators of the socioeconomic status of those in the neighbourhood: the share of highly educated individuals and the share of high-income individuals. These socioeconomic characteristics of neighbourhoods seem to have a strong relationship with the likelihood of leaving the neighbourhood. A one standard deviation (17 percentage points) higher share of people with tertiary education is associated with a $26 \%$ higher odds of out-migration, whereas a standard deviation higher share of high-income individuals in the neighbourhood is associated with a decrease in the odds of out-migration of close to $30 \%$. We are unsure about how to explain the somewhat puzzling result with regard to the neighbourhood educational level. However, we may tentatively suggest that the relatively high out-migration from highly educated neighbourhoods reflects that such neighbourhoods may attract more mobile people, or that it captures out-migration from relatively young neighbourhoods (including areas with a high density of students) that people leave when they are about to establish a family.

In sum, members of the population of Danish-born individuals (natives and descendants of immigrants) tend to move out of neighborhoods that have high proportions of minorities. Their odds of doing so are even higher if the share of minorities has increased over the last few years. If the population of the larger extralocal area is more diverse, the likelihood of outmigration is a little bit lower.

In a second step, we split up this population of individuals born in Denmark into two segments: those who have no immigrant background or naturalized parents (denoted natives), and those who are descendants of non-naturalized immigrants (denoted descendants). The 
separate analysis of out-migration among natives and descendants reveals that the phenomenon of out-migration related to minority concentration is only observed among the native population. The coefficients in the models for the native population are similar in size to those from the models for the total population. In our sample of descendants, the coefficients for the proportion of minorities are smaller and non-significant, while the coefficients for change in the proportion of minorities are negative and non-significant.

In sum, members of the population of Danish-born individuals (natives and descendants of immigrants) tend to move out of neighbourhoods that have high proportions of minorities. Their odds of doing so are even higher if the share of minorities has increased over the last few years. If the population of the larger extralocal area $(\mathrm{k}=51200)$ is more diverse, the likelihood of out-migration is a little bit lower. Our analysis also supports the hypothesis that outmigration from neighbourhoods with high and increasing shares of minorities is higher among natives than among descendants. In our sample of descendants, the coefficient for the proportion of minorities is smaller and non-significant, while the coefficient for change in the proportion of visible minorities is negative and non-significant. Only various individual and local control variables (cf supplementary materials S3.1-3.3) are statistically significantly associated with a descendant's likelihood of out-migration.

\subsection{The importance of parenthood}

Our fourth hypothesis stated that the response to changes in the local concentration of minorities is weaker among childless natives than among native parents. Wessel and Nordvik (2019) suggested that parents may be more sensitive to the local concentration of minorities than non-parents, for instance because of concerns over potential adverse effects of their children attending schools or residing in neighbourhoods with high minority concentrations.

In order to assess this plausible interaction, we have run an analysis using native individuals aged 25-45, who represent those who are most likely to be living with children of school age. This subsample was divided into two groups; parents and non-parents. We have then estimated our main model specifications on these subsamples. The main results from these estimations are given in Table 5.

The results from our estimations largely confirm that parents do appear to be more sensitive to the population composition of their neighbourhoods, and to changes in this composition, than non-parents. Consider our largest model specification (Model 3) and the coefficients for the local concentration of minorities and the change in this concentration. For childless individuals the coefficient for the level of concentration is about one-third of the 
corresponding coefficient for individuals who are parents (0.502 vs. 1.555), and the difference is statistically significant. The higher sensitivity of parents becomes even clearer when we compare the corresponding coefficients for the change in concentration of minorities. The coefficient for childless individuals is near zero and non-significant, while the coefficient for parents is positive $(\mathrm{B}=1.005)$ and statistically significant.

These results thus support Wessel and Nordvik's (2019) suggestion that individuals with young children have a higher sensitivity to characteristics of the local environment and changes in such characteristics. We do not know exactly what produces these associations, however, and there are some important possible explanations, even when we have controlled for some aspects of the SES composition of the neighbourhood. For example, the possibility remains that characteristics of housing stock is correlated with the concentration of minorities. Neighbourhoods with high minority concentrations are often characterized by a high density of apartment buildings. Individuals with children living in such areas most likely also have a higher and perhaps even increasing housing demand, and may be forced to look elsewhere to be able to find larger dwellings.

\subsection{Robustness check: Does the definition of migrant groups matter?}

As discussed above, the definition of the minority group that we use in our main analysis is somewhat arbitrarily chosen and delineated. We therefore find it pertinent to ask whether the results are highly sensitive to the definition of the minority group. It is conceivable that our results would look different had we used another grouping of individuals. We tested the sensitivity of our results to the choice of grouping by re-estimating the same models, while defining the minority group as individuals originating from 'non-Western' countries, and from 'predominantly Muslim' countries, respectively.

As is clear from the results presented in the supplementary materials (S6.1), we observe the same general pattern for all the three definitions of the minority group. For all three definitions, the coefficient for the association between the local concentration of the minority group and out-migration is estimated at around 0.9. Evidently, the choice of grouping does not matter very much in this case.

\subsection{A discussion of modelling 'flight': moves to areas with lower minority concentrations}

Throughout this paper, we have used the terms 'flight' and 'out-migration' more or less interchangeably. Strictly speaking, one could argue that these are two related but separate phenomena. While out-migration is a move to any area, we define a flight-type move as a move 
to an area with a lower concentration of minorities. In order to make claims about flight in this narrower sense, we have conducted an analysis similar to our main analysis, but where the dependent variable is a dummy taking the value 1 if an individual moves to a neighbourhood with a lower concentration of (visible) minorities, and 0 otherwise. However, such an analysis involves a methodological problem; regression to the mean. When moving, people who live in neighbourhoods with very high concentrations of minorities will usually move to neighbourhoods with lower such concentrations - even if moves are completely random. The opposite is true for people living in neighbourhoods with low concentrations. The reason is that, closer to the top (bottom) of the distribution, there are fewer neighbourhoods one could move to that have a higher (lower) concentration. Thus, when we define 'native flight' to be a move to a lower-concentration neighbourhood, we, almost by definition, find that a higher concentration in the local neighbourhood is strongly positively associated with native flight. In other words, using such a definition of 'native flight' means that our estimates are upwardly biased. We have included a set of results using the flight-type outcome definition in the supplementary material. For the reasons given above, we urge the reader to be cautious when interpreting these results.

\section{Discussion and Conclusions}

We found that the out-migration probabilities in our pooled sample of natives and descendants are higher in neighbourhoods with higher proportions of minorities and neighbourhoods with increasing shares of minorities, and that it is lower in areas with higher proportions of minorities in the extralocal neighbourhoods. We further found that this pattern was stronger among the natives, but weaker, partly reversed and non-significant among descendants of immigrants. In other words, we find evidence of moving patterns that correspond with native out-migration in Copenhagen.

Why do people leave neighbourhoods where the share of minorities in the population is high or increasing? As mentioned above, one obvious answer is that people leave such areas because they prefer to live in proximity of their own group. Individuals' preferences for neighbourhood composition may be more or less diversity-oriented, and they may prefer to live in relatively ethnically homogeneous areas. In 2002, the European Social Survey asked respondents about their preferences for neighbourhood ethnic composition. The opinion held by Danes was striking: 37 per cent of Danes stated that they preferred to live in an ethnically 
homogeneous area. This is markedly more negative to diversity than views held, on average, by the Norwegian (23\%), Swedish (20\%) and Finnish populations (31\%). When we restrict the sample to those living in the metropolitan area including the capital city, levels are somewhat lower. Danes in the Copenhagen area were less sceptical to neighbourhood diversity, but still more than a quarter (27\%) expressed negative opinions about residing in a diverse neighbourhood, markedly higher than the populations of the Oslo and Stockholm metropolitan areas.

Another, related, explanation is that parents may hold preferences for schools with a low concentration of ethnic minority pupils, such that native parents of young children move selectively to avoid schools with high minority concentrations. Analyses by Wessel and Nordvik (2019) suggest that this may be the case in Norway, and our analysis of parents and non-parents clearly support such an argument. Additionally, we cannot rule out alternative explanations such as the possibility that the native out-migration we observe is primarily driven by neighbourhood characteristics other than their ethnic composition, or by selection processes. In other words, his study does not provide direct evidence that natives are motivated to move by a preference for ethnically homogeneous neighbourhoods. A number of other factors besides ethnic composition may affect the propensity to move out of neighbourhoods with high and/or increasing proportions of visible minorities. Regardless of the exact mechanism producing native out-migration, this study has documented that natives do tend to move out of neighbourhoods with high minority concentrations in Copenhagen. This process likely contributes to ethnic segregation on the urban area. In this regard, our results are consistent with some recent studies in other countries, e.g. Aldén et al (2014), Wessel and Nordvik (2019) and McAvay (2018), who find patterns of native out-migration in Sweden, Norway and France, respectively.

Nevertheless, our study also has several limitations worth noting. First, our sample is endogenously conditioned. The natives living in neighbourhoods with high concentrations of minorities are the natives who have not already moved out. This may bias our estimates downwards. Second, the set of control variables we include is by no means comprehensive, and other factors (at the neighbourhood or individual level, including characteristics of the local housing market) may drive our results. Third, we only analyse a limited number of years. Undoubtedly, our conclusions would have been stronger if we had been able to use more finegrained panel data. Fourth, we do not have information about individuals' preferences, and thus cannot directly test whether our results chiefly reflect neighbourhood preferences. Fifth, we acknowledge the fact that our analyses are sensitive to issues related to comparing logistic 
regression coefficients across models (Mood 2010) and that the explained variance in most models is modest. Finally, most of the theoretical discussions in this article, and in much of the literature on residential segregation, assume that individuals interact with their neighbours or somehow care about who resides in their neighbourhood. This may be a strong assumption with limited validity. If neighbourhoods are not an important locus of interaction, this would undercut several theoretical contributions to segregation research, but it would not invalidate our conclusions. However, we do believe that this may be a valuable research topic, as several theories about neighbourhood effects implicitly or explicitly assume that neighbours interact and affect each other, and that neighbourhood differences are not primarily driven by selection.

These limitations notwithstanding, this study has contributed to the literature on segregation and mobility in several ways. We have used high-quality register data and the novel technique of individualized scalable neighbourhoods to model out-migration in Copenhagen. Our results are the first of their kind from Copenhagen, and speaks to several salient issues in the extant literature. Ethnic group identifies must influence migration processes in urban areas, because our results differ sharply between natives and descendants. Our analyses also highlight the role of children as an important aspect of people's motivations for migration. The study also offer discussions on how to define and operationalize out-migration and flight.

To researchers and governments who are struggling with issues related to the integration of minorities, the evidence presented here may serve as a useful reminder that individuals respond to their environments in ways that sometimes are in conflict with political goals and the targets of social planners. If neighbourhood diversity is pursued as a political goal, and there may be good reasons to pursue it, one must take into account the potential feedback mechanisms of individuals moving away from areas with large and increasing shares of minorities.

\section{References}

Aldén, L., Hammarstedt, M. and Neuman, E. (2015). Ethnic segregation, tipping behavior, and native residential mobility. International Migration Review, 49(1), 36-69.

Andersen, H. S. (2017). Selective moving behaviour in ethnic neighbourhoods: white flight, white avoidance, ethnic attraction or ethnic retention?. Housing Studies, 32(3), 296-318. 
Andersson, R. (2013). Reproducing and Reshaping Ethnic Residential Segregation in Stockholm: The Role of Selective Migration Moves. Geografiska Annaler: Series B, Human Geography 95 (2): 163-87.

Betts, J. R. and Fairlie, R. W. (2001). Explaining Ethnic, Racial, and Immigrant Differences in Private School Attendance. Journal of Urban Economics 50 (1): 26-51.

Bolt, G., Van Kempen, R. and Van Ham, M. (2008). Minority ethnic groups in the Dutch housing market: Spatial segregation, relocation dynamics and housing policy. Urban Studies, 45(7), 1359-1384.

Borjas, G. J. (2006). Native internal migration and the labor market impact of immigration. Journal of Human Resources, 41(2), 221-258.

Bruch, E. E. and Mare, R. D. (2006). Neighborhood choice and neighborhood change. American Journal of Sociology, 112(3), 667-709.

Bråmå, Å. (2006). 'White Flight'? The Production and Reproduction of Immigrant Concentration Areas in Swedish Cities, 1990-2000. Urban Studies 43 (7): 1127-46.

Bråmå, Å. (2008). Dynamics of Ethnic Residential Segregation in Göteborg, Sweden, 19952000. Population, Space and Place 14 (2): 101-17.

Clark, W. A. (2002). Ethnic preferences and ethnic perceptions in multi-ethnic settings. Urban Geography, 23(3), 237-256.

Clark, W. A. and Fossett, M. (2008). Understanding the social context of the Schelling segregation model. Proceedings of the National Academy of Sciences, 105(11), 41094114.

Clark, W. A. and Coulter, R. (2015). Who wants to move? The role of neighbourhood change. Environment and Planning A, 47(12), 2683-2709.

Crowder, K. (2000). The Racial Context of White Mobility: An Individual-Level Assessment of the White Flight Hypothesis. Social Science Research 29 (2): 223-57.

Crowder, K., Hall, M. and Tolnay, S. E. (2011). Neighborhood Immigration and Native outMigration. American Sociological Review 76 (1): 25-47.

Crowder, K., Pais, J. and South, S. J. (2012). Neighborhood diversity, metropolitan constraints, and household migration. American Sociological Review, 77(3), 325-353.

Crowder, K. and South, S. J. (2008). Spatial Dynamics of White Flight: The Effects of Local and Extralocal Racial Conditions on Neighborhood out-Migration. American Sociological Review 73 (5): 792-812. 
Damm, A. P. and Schultz-Nielsen, M. L. (2008). The Construction of Neighbourhoods and Its Relevance for the Measurement of Social and Ethnic Segregation: Evidence from Denmark. IZ Discussion Paper \#3719.

Edin, P.-A., Fredriksson, P. and Åslund, O. (2003). Ethnic Enclaves and the Economic Success of Immigrants-Evidence from a Natural Experiment. The Quarterly Journal of Economics, 118(1), 329-357. doi:10.1162/00335530360535225

Emerson, M. O., Chai, K. J. and Yancey, G. (2001). Does race matter in residential segregation? Exploring the preferences of white Americans. American Sociological Review, 922-935.

Farley, R., Steeh, C., Krysan, M., Jackson, T. and Reeves, K. (1994). Stereotypes and segregation: Neighborhoods in the Detroit area. American Journal of Sociology, 750780.

Farley, R., Fielding, E. L. and Krysan, M. (1997). The residential preferences of blacks and whites: A four-metropolis analysis. Housing Policy Debate, 8(4), 763-800.

Filer, R. (1992). The effect of immigrant arrivals on migratory patterns of native workers. In: Immigration and the workforce: Economic consequences for the United States and source areas (pp. 245-270). University of Chicago Press.

Fossett, M. (2006). Ethnic Preferences, Social Distance Dynamics, and Residential Segregation: Theoretical Explorations Using Simulation Analysis*. Journal of Mathematical Sociology, 30(3-4), 185-273.

French, K. N. (2014). Exploring socioeconomic characteristics of ethnically divided neighbourhoods. Chapter 16 in: Lloyd, C. D., Shuttleworth, I. G. and Wong, D. W. S. (eds.), Social-Spatial Segregation. Concepts, Processes and Outcomes. Bristol/Chicago: Policy Press

Frey, W. H. (1995). Immigration and internal migration flight from US metropolitan areas: toward a new demographic Balkanisation. Urban Studies, 32(4-5), 733-758.

Frey, W. H. (1996). Immigration, domestic migration, and demographic balkanization in America: new evidence for the 1990s. Population and Development Review, 741-763.

Galloway, T. A. and Aaberge, R. (2005). Assimilation effects on poverty among immigrants in Norway. Journal of Population Economics, 18(4), 691-718.

Goodwin-White, J. (2018). The shaping of selection: Secondary migration, scale, and changing immigrant geographies. Population, Space and Place, 24(8), e2158.

Green-Pedersen, C. and Krogstrup, J. (2008). Immigration as a political issue in Denmark and Sweden. European journal of political research, 47(5), 610-634. 
Hall, M. and Crowder, K. (2014). Native out-migration and neighborhood immigration in new destinations. Demography, 51(6), 2179-2202.

van Ham, M. and Feijten, P. (2008). Who wants to leave the neighbourhood? The effect of being different from the neighbourhood population on wishes to move. Environment and Planning A, 40(5), 1151-1170.

van Ham, M. and Manley, D. (2014). Segregation, choice-based letting and social housing: how housing policy can affect the segregation process. Chapter 11 in: Lloyd, C. D., Shuttleworth, I. G. and Wong, D. W. S. (eds.), Social-Spatial Segregation. Concepts, Processes and Outcomes. Bristol/Chicago: Policy Press

Hermansen, A. S. (2013). Occupational Attainment among Children of Immigrants in Norway: Bottlenecks into Employment-equal Access to Advantaged Positions? European Sociological Review 29 (3): 517-34.

Husted, L., Skyt Nielsen, H., Rosholm, M. and Smith, N. (2001). Employment and wage assimilation of male first-generation immigrants in Denmark. International Journal of Manpower, 22(1/2), 39-71.

Hwang, S. (2014). A tale of two cities: residential segregation in St Louis and Cincinnati. Chapter 13 in: Lloyd, C. D., Shuttleworth, I. G. and Wong, D. W. S. (eds.), SocialSpatial Segregation. Concepts, Processes and Outcomes. Bristol/Chicago: Policy Press

Jensen, P. R. and Würtz, A. (2011). "The Effect of Immigrant Concentration in Schools on Native and Immigrant Children's Reading and Math Skills." Economics of Education Review 30(6):1503-1515.

Kristensen, H. (2002). Social housing policy and the welfare state: a Danish perspective. Urban Studies, 39(2), 255-263.

Krysan, M. (2002). Whites who say they'd flee: Who are they, and why would they leave?. Demography, 39(4), 675-696.

Krysan, M., Couper, M. P., Farley, R. and Forman, T. A. (2009). Does race matter in neighborhood preferences? Results from a video experiment. American Journal of Sociology, 115(2), 527-559.

Ley, D., and Tutchener J. (2001). Immigration, Globalisation and House Prices in Canada's Gateway Cities. Housing Studies 16 (2): 199-223.

Lloyd, C. D., Shuttleworth, I. G. and Wong, D. W. S. (eds.) (2014). Social-Spatial Segregation. Concepts, Processes and Outcomes. Bristol/Chicago: Policy Press

Longva, P. and Raaum, O. (2003). Earnings assimilation of immigrants in Norway-A reappraisal. Journal of Population Economics, 16(1), 177-193. 
Massey, D. S., Condran, G. A. and Denton, N. A. (1987). The effect of residential segregation on black social and economic well-being. Social Forces, 66(1), 29-56.

Massey, D. S., Gross, A. B. and Shibuya, K. (1994). Migration, segregation, and the geographic concentration of poverty. American Sociological Review, 425-445.

McAvay, H. (2018). The ethnoracial context of residential mobility in France: Neighbourhood out-migration and relocation, Population, Space and Place, 24(6)

Ministry of Refugees, Immigration and Integration Affairs (2004). Regeringens strategi mod ghettoisering. Copenhagen: Ministeriet for Flygtninge, Indvandrere og Integration

Møller, I. H. and Larsen, J. E. (2015). The Socioeconomic and Ethnic Segregation of Living Conditions in Copenhagen. Revista Crítica de Ciências Sociais, (108), 7-30.

Mood, C. (2010). Logistic regression: Why we cannot do what we think we can do, and what we can do about it. European Sociological Review, 26(1), 67-82.

Moody, J. (2001). Race, school integration, and friendship segregation in America. American Journal of Sociology, 107(3), 679-716.

Musterd, S. and van Gent, W. (2012). Residential location and housing moves of immigrants and natives in the Amsterdam metropolitan context. Chapter 5 in: Finney, N. and Catney, G. (eds.), Minority internal migration in Europe. Surrey/Burlington: Ashgate.

Nielsen, M. M. and Hennerdal, P. (2017). Changes in the residential segregation of immigrants in Sweden from 1990 to 2012: Using a multi-scalar segregation measure that accounts for the modifiable areal unit problem. Applied Geography, 87, 73-84.

Östh, J. (2013). Introducing the EquiPop software - an application for the calculation of $k$ nearest neighbour contexts/neighbourhoods. Uppsala Univeristy.

Östh, J., Clark, W. A. V. and Malmberg, B. (2015). Measuring the Scale of Segregation Using k-Nearest Neighbor Aggregates. Geographical Analysis 47 (1): 34-49.

Östh, J., Malmberg, B. and Andersson, E. K. (2014). Analysing Segregation Using Individualised Neighbourhoods. Socio-Spatial Segregation: Concepts, Processes and Outcomes, 135-62.

Pais, J. F., South, S. J. and Crowder, K. (2009). White Flight Revisited: A Multiethnic Perspective on Neighborhood out-Migration. Population Research and Policy Review 28 (3): 321-46.

Pew Research Center (2011). The Future of the Global Muslim Population: Projections for 2010-2030. Pew Research Center. Forum on Religion and Public Life, Washington, D.C 
Rathelot, R. and Safi, M. (2014). Local ethnic composition and natives' and immigrants' geographic mobility in France, 1982-1999. American Sociological Review, 79(1), 43 64.

Sabater, A. and Finney, N. (2014). Demographic understandings of changes in ethnic residential segregation across the life course. Chapter 12 in: Lloyd, C. D., Shuttleworth, I. G. and Wong, D. W. S. (eds.), Social-Spatial Segregation. Concepts, Processes and Outcomes. Bristol/Chicago: Policy Press

Schelling, T. C. (1971). Dynamic Models of Segregation. Journal of Mathematical Sociology $1(2): 143-86$.

Shuttleworth, I. G., Gould, M. and Barr, P. (2014). Perspectives on social segregation and migration: spatial scale, mixing and place. Chapter 9 in: Lloyd, C. D., Shuttleworth, I. G. and Wong, D. W. S. (eds.), Social-Spatial Segregation. Concepts, Processes and Outcomes. Bristol/Chicago: Policy Press

Simpson, L. and Finney, N. (2009). Spatial patterns of internal migration: evidence for ethnic groups in Britain. Population, Space and Place, 15(1), 37-56.

South, S. J. and Crowder, K. D. (1997). Escaping distressed neighborhoods: Individual, community, and metropolitan influences. American Journal of Sociology, 1040-1084.

South, S. J. and Crowder, K. D. (1998). Leaving the 'hood: Residential mobility between black, white, and integrated neighborhoods. American Sociological Review, 17-26.

Statistics Denmark (n.a.). StatBank Denmark. BOL101 Dwellings by region, type of resident, use, tenure, ownership and year of construction (2010-2017) (online database). Retrieved from http://www.statbank.dk/statbank5a/default.asp?w=1920 [accessed september 6th 2017]

Wessel, T. and Nordvik, V. (2019). Mixed neighbourhoods and native out-mobility in the Oslo region: The importance of parenthood. Urban Studies, 56(5), 885-905.

Wessel, T., Andersson, R., Kauppinen, T. and Andersen, H. S. (2016). "Spatial Integration of Immigrants in Nordic Cities The Relevance of Spatial Assimilation Theory in a Welfare State Context." Urban Affairs Review, 1078087416638448.

Wilson, W. J. and Taub, R. P. (2006). There goes the neighborhood: Racial, ethnic, and class tensions in four Chicago neighborhoods and their meaning for America. New York, NY: Knopf.

Wilson, K. L. and Portes, A. (1980). Immigrant Enclaves: An Analysis of the Labor Market Experiences of Cubans in Miami. American Journal of Sociology, 86(2), 295-319. doi:10.1086/227240 
Woldoff, R. A. (2011). White flight/Black flight: The dynamics of racial change in an American neighborhood. Ithaca, NY: Cornell University Press. 


\section{List of tables}

\# Title

1 Population groups and sizes in the Copenhagen metropolitan area, 1980-2019

2 Descriptives for individual-level variables

3 Descriptives for neighbourhood-level variables

4 Main results from three models of out-migration on full population, natives and descendants

5 Main results from three models of out-migration by native parents and childless 
TABLE 1. POPULATION GROUPS AND SIZES IN COPENHAGEN METROPOLITAN AREA 1980-2019.

\begin{tabular}{|c|c|c|c|c|c|c|c|c|c|c|c|c|}
\hline \multicolumn{3}{|c|}{$\underline{1980}$} & \multicolumn{2}{|l|}{$\underline{2001}$} & \multicolumn{2}{|l|}{$\underline{2006}$} & \multicolumn{2}{|l|}{$\underline{2011}$} & \multicolumn{2}{|l|}{$\underline{2015}$} & \multicolumn{2}{|l|}{$\underline{2019}$} \\
\hline$\#$ & Country & $n$ & Country & $n$ & Country & $n$ & Country & $n$ & Country & $n$ & Country & $n$ \\
\hline 1 & Sweden & 8,190 & Turkey & 24,048 & Turkey & 26,519 & Turkey & 28,856 & Turkey & 30,078 & Turkey & 31,340 \\
\hline 2 & Germany & 7,954 & Pakistan & 15,863 & Pakistan & 16,635 & Pakistan & 18,211 & Pakistan & 20,403 & Pakistan & 21,646 \\
\hline 3 & Pakistan & 6,688 & Yugoslavia & 9,027 & Iraq & 9,297 & Iraq & 11,097 & Iraq & 12,467 & Iraq & 13,619 \\
\hline 4 & Norway & 6,240 & Iraq & 6,718 & Yugoslavia & 8,614 & Poland & 8,979 & Poland & 11,304 & Poland & 12,469 \\
\hline 5 & Turkey & 6,121 & Sweden & 6,648 & Morocco & 7,271 & Yugoslavia & 8,048 & Morocco & 8,322 & Germany & 9,558 \\
\hline 6 & Yugoslavia & 4,744 & Morocco & 6,552 & Sweden & 6,501 & Morocco & 7,884 & Germany & 8,173 & India & 8,838 \\
\hline 7 & Poland & 3,577 & Germany & 6,075 & Lebanon & 6,095 & Germany & 7,378 & Yugoslavia & 7,451 & Morocco & 8,721 \\
\hline 8 & UK & 3,498 & Norway & 5,616 & Germany & 6,084 & Sweden & 6,817 & Iran & 7,417 & Iran & 8,634 \\
\hline 9 & USA & 2,719 & Iran & 5,308 & Norway & 6,023 & Lebanon & 6,617 & Sweden & 7,339 & Sweden & 8,177 \\
\hline 10 & Finland & 2,169 & Lebanon & 5,259 & Iran & 5,880 & Norway & 6,312 & Lebanon & 7,336 & China & 7,933 \\
\hline 11 & Iceland & 1,815 & Poland & 5,181 & Poland & 5,693 & Iran & 6,195 & Norway & 6,729 & UK & 7,825 \\
\hline 12 & Morocco & 1,729 & Somalia & 5,137 & Somalia & 5,158 & Somalia & 5,928 & Somalia & 6,632 & Lebanon & 7,719 \\
\hline 13 & USSR & 1,466 & UK & 5,049 & UK & 4,962 & China & 5,904 & China & 6,554 & Yugoslavia & 7,132 \\
\hline 14 & France & 1,262 & $\mathrm{BiH}$ & 3,131 & China & 4,597 & UK & 5,548 & UK & 6,280 & Norway & 7,114 \\
\hline 15 & India & 1,133 & USA & 3,037 & $\mathrm{BiH}$ & 3,460 & Philippines & 5,059 & India & 5,940 & Somalia & 7,059 \\
\hline 16 & Italy & 1,072 & China & 2,612 & USA & 3,370 & India & 4,639 & Philippines & 5,594 & Romania & 6,147 \\
\hline 17 & Hungary & 823 & Philippines & 2,491 & Philippines & 3,211 & USA & 3,966 & Afghanistan & 4,410 & Philippines & 5,860 \\
\hline 18 & Spain & 817 & Iceland & 2,286 & Iceland & 2,906 & $\mathrm{BiH}$ & 3,877 & USA & 4,386 & Italy & 5,786 \\
\hline 19 & Philippines & 749 & Thailand & 2,220 & Thailand & 2,865 & Afghanistan & 3,548 & Romania & 4,258 & USA & 5,659 \\
\hline 20 & Chile & 696 & France & 2,192 & India & 2,833 & Thailand & 3,548 & $\mathrm{BiH}$ & 4,224 & Afghanistan & 5,372 \\
\hline & ulation & $1,214,382$ & & $1,205,339$ & & $1,211,542$ & & $1,209,627$ & & $1,275,332$ & & $1,332,152$ \\
\hline & & 76,841 & & 167,133 & & 189,250 & & 227,083 & & 262,033 & & 305,588 \\
\hline$c_{r}$ & on of the & $6.3 \%$ & & $13.9 \%$ & & $15.6 \%$ & & $18.8 \%$ & & $20.5 \%$ & & 22.9 \\
\hline
\end{tabular}

Source: Own calculcations from population register data. 
TABLE 2. DESCRIPTIVE STATISTICS OF ANALYSIS VARIABLES

\begin{tabular}{|c|c|c|c|c|c|c|c|c|c|}
\hline \multirow{2}{*}{$\underline{\text { Variable }}$} & \multirow[t]{2}{*}{ Definition/category } & \multicolumn{2}{|l|}{ All periods } & \multicolumn{2}{|l|}{$\underline{2007}$} & \multicolumn{2}{|l|}{$\underline{2011}$} & \multicolumn{2}{|l|}{$\underline{2014}$} \\
\hline & & $m$ & s.d. & $m$ & s.d. & $m$ & s.d. & $m$ & s.d. \\
\hline Out-migration & Moved to new grid cell & 0.117 & 0.321 & 0.113 & 0.317 & 0.114 & 0.317 & 0.123 & 0.329 \\
\hline Flight & Moved to with lower \% minorities & 0.060 & 0.237 & 0.059 & 0.236 & 0.057 & 0.232 & 0.062 & 0.242 \\
\hline \multirow[t]{3}{*}{ Migration status } & Native & 0.826 & 0.379 & 0.852 & 0.355 & 0.823 & 0.382 & 0.805 & 0.397 \\
\hline & Immigrant & 0.161 & 0.367 & 0.138 & 0.345 & 0.164 & 0.370 & 0.179 & 0.383 \\
\hline & Descendant of immigrants & 0.013 & 0.114 & 0.010 & 0.097 & 0.013 & 0.113 & 0.016 & 0.127 \\
\hline \multirow[t]{3}{*}{ Minority status } & Visible minority & 0.097 & 0.295 & 0.082 & 0.275 & 0.098 & 0.298 & 0.108 & 0.310 \\
\hline & Non-Western & 0.113 & 0.316 & 0.097 & 0.297 & 0.115 & 0.319 & 0.125 & 0.331 \\
\hline & Muslim Country & 0.059 & 0.236 & 0.052 & 0.223 & 0.060 & 0.237 & 0.065 & 0.246 \\
\hline \multirow[t]{2}{*}{ Sex } & Male & 0.482 & 0.500 & 0.480 & 0.500 & 0.482 & 0.500 & 0.484 & 0.500 \\
\hline & Female & 0.518 & & 0.520 & & 0.518 & & 0.516 & \\
\hline \multirow[t]{3}{*}{ Age } & $25-44$ & 0.464 & 0.499 & 0.469 & 0.499 & 0.463 & 0.499 & 0.460 & 0.498 \\
\hline & $45-64$ & 0.333 & 0.471 & 0.335 & 0.472 & 0.334 & 0.472 & 0.330 & 0.470 \\
\hline & $65+$ & 0.203 & 0.402 & 0.196 & 0.397 & 0.203 & 0.402 & 0.209 & 0.407 \\
\hline \multirow[t]{3}{*}{ Education } & Low: Primary/lower secondary & 0.220 & 0.414 & 0.241 & 0.428 & 0.219 & 0.413 & 0.201 & 0.401 \\
\hline & Medium: Completed secondary & 0.381 & 0.486 & 0.396 & 0.489 & 0.380 & 0.485 & 0.368 & 0.482 \\
\hline & High: Tertiary education & 0.397 & 0.489 & 0.360 & 0.480 & 0.399 & 0.490 & 0.429 & 0.495 \\
\hline \multirow[t]{3}{*}{ No. of children } & Childless & 0.678 & 0.467 & 0.690 & 0.463 & 0.676 & 0.468 & 0.669 & 0.470 \\
\hline & 1-2 children & 0.277 & 0.447 & 0.266 & 0.442 & 0.279 & 0.448 & 0.284 & 0.451 \\
\hline & 3 or more children & 0.045 & 0.208 & 0.044 & 0.205 & 0.046 & 0.209 & 0.046 & 0.211 \\
\hline \multirow[t]{2}{*}{ Union status } & Single & 0.433 & 0.495 & 0.436 & 0.496 & 0.432 & 0.495 & 0.431 & 0.495 \\
\hline & Married or cohabiting & 0.567 & & 0.564 & & 0.568 & & 0.569 & \\
\hline \multirow[t]{2}{*}{ Labour market } & Not currently employed & 0.102 & 0.303 & 0.033 & 0.179 & 0.132 & 0.338 & 0.138 & 0.345 \\
\hline & Currently employed & 0.898 & & 0.967 & & 0.868 & & 0.862 & \\
\hline \multicolumn{2}{|c|}{ Sample size (excluding all missing values) } & 2517583 & $(2369115)$ & 811418 & (770458) & 836702 & (787629) & 869463 & (811028) \\
\hline
\end{tabular}

Source: Own calculcations from population register data. 
TABLE 3. DESCRIPTIVE STATISTICS OF NEIGHBORHOOD VARIABLES

$\underline{\text { Scale Variable }}$

$k=800$

$\%$ of visible minorities among $\mathrm{kNN}$

$\%$ of non-western individuals among kNN

$\%$ of muslim background individuals among kNN

Change in \% of visible minorities among kNN

Change in \% of non-western individuals among kNN

Change in \% of muslim background individuals among kNN $k=51200$

$\%$ of visible minorities among kNN

$\%$ of non-western individuals among kNN

$\%$ of muslim background individuals among kNN

$\%$ of highly educated persons among kNN

$\%$ of high income earners among kNN

Source: Own calculcations from population register data.

\begin{tabular}{|c|c|c|c|c|c|c|c|}
\hline All periods & \multicolumn{2}{|c|}{$\underline{2007}$} & \multicolumn{2}{|c|}{$\underline{2011}$} & \multicolumn{2}{|c|}{$\underline{2014}$} & \\
\hline$m$ & & & & & & \multicolumn{2}{|c|}{ s.d. } \\
\hline 0.107 & 0.11 & 0.103 & 0.11 & 0.113 & 0.11 & 0.121 & 0.12 \\
\hline 0.124 & 0.12 & 0.119 & 0.12 & 0.130 & 0.12 & 0.138 & 0.13 \\
\hline 0.070 & 0.09 & 0.068 & 0.09 & 0.072 & 0.09 & 0.076 & 0.09 \\
\hline 0.010 & 0.02 & 0.012 & 0.02 & 0.010 & 0.03 & 0.007 & 0.02 \\
\hline 0.010 & 0.02 & 0.013 & 0.03 & 0.011 & 0.03 & 0.007 & 0.02 \\
\hline 0.004 & 0.02 & 0.005 & 0.02 & 0.004 & 0.02 & 0.003 & 0.02 \\
\hline 0.107 & 0.05 & 0.103 & 0.05 & 0.112 & 0.05 & 0.120 & 0.05 \\
\hline 0.123 & 0.05 & 0.119 & 0.05 & 0.129 & 0.05 & 0.137 & 0.06 \\
\hline 0.069 & 0.04 & 0.067 & 0.04 & 0.071 & 0.04 & 0.074 & 0.04 \\
\hline 0.318 & 0.20 & 0.371 & 0.14 & 0.405 & 0.15 & 0.427 & 0.15 \\
\hline 0.122 & 0.08 & 0.121 & 0.08 & 0.123 & 0.09 & 0.122 & 0.09 \\
\hline
\end{tabular}


TABLE 4. MAIN RESULTS FOR NEIGHBORHOOD COMPOSITION FROM THREE MODELS ACROSS THREE POPULATION DEFINITIONS.

\begin{tabular}{|c|c|c|c|c|c|c|c|}
\hline & \multirow[b]{2}{*}{ Variable } & \multicolumn{2}{|l|}{ Model 1} & \multicolumn{2}{|c|}{ Model 2} & \multicolumn{2}{|c|}{ Model 3} \\
\hline & & $b$ & $S E$ & & & & \\
\hline \multicolumn{8}{|l|}{ Full } \\
\hline & Proportion of visible minorities among kNN 800 & $1.137^{* * *}$ & 0.026 & $1.111 * * *$ & 0.030 & $0.912 * * *$ & 0.032 \\
\hline & Change in proportion of visible minorities kNN 800 & $-4.431 * * *$ & 0.109 & $-0.517 * * *$ & 0.109 & $0.271 *$ & 0.113 \\
\hline & Proportion of visible minorities among kNN 51200 & -0.026 & 0.054 & $-0.372 * * *$ & 0.061 & $-0.303 * * *$ & 0.064 \\
\hline \multicolumn{8}{|l|}{ Natives } \\
\hline & Proportion of visible minorities among kNN 800 & $1.114 * * *$ & 0.027 & $1.068 * * *$ & 0.031 & $3.32 * * *$ & 0.035 \\
\hline & Change in proportion of visible minorities kNN 800 & $-4.500 * * *$ & 0.111 & $-0.497 * * *$ & 0.112 & $1.529 * * *$ & 0.133 \\
\hline & Proportion of visible minorities among kNN 51200 & -0.037 & 0.055 & $-0.390 * * *$ & 0.062 & $-0.89 * * *$ & 0.083 \\
\hline \multicolumn{8}{|c|}{ Descendants } \\
\hline & Proportion of visible minorities among kNN 800 & 0.088 & 0.125 & 0.169 & 0.145 & 0.256 & 0.152 \\
\hline & Change in proportion of visible minorities kNN 800 & $-1.969 * * *$ & 0.554 & -0.863 & 0.567 & -0.933 & 0.595 \\
\hline & Proportion of visible minorities among kNN 51200 & -0.324 & 0.350 & -0.333 & 0.367 & -0.056 & 0.391 \\
\hline \multicolumn{2}{|c|}{ Controls for SES neighborhood variables } & \multicolumn{2}{|l|}{ No } & \multicolumn{2}{|l|}{ Yes } & \multicolumn{2}{|l|}{ Yes } \\
\hline \multicolumn{2}{|c|}{ Controls for individual variables } & \multicolumn{2}{|l|}{ No } & \multicolumn{2}{|l|}{ No } & \multicolumn{2}{|l|}{ Yes } \\
\hline
\end{tabular}

Source: Own calculcations from population register data. 
TABLE 5. MAIN RESULTS FOR NEIGHBORHOOD COMPOSITION FROM THREE MODELS FOR CHILDLESS NATIVES AND PARENT NATIVES AGED $25-45$.

\begin{tabular}{|c|c|c|c|c|c|c|c|}
\hline \multirow{3}{*}{$\begin{array}{l}\text { Population } \\
\text { Childless }\end{array}$} & \multirow[b]{2}{*}{ Variable } & \multicolumn{2}{|l|}{ Model 1} & \multicolumn{2}{|c|}{ Model 2} & \multicolumn{2}{|c|}{ Model 3} \\
\hline & & $b$ & \multicolumn{2}{|c|}{$b$} & \multirow{2}{*}{\multicolumn{2}{|c|}{$b$}} & \multirow[t]{2}{*}{ E } \\
\hline & & & & & & & \\
\hline & Proportion of visible minorities among kNN 800 & $0.096 *$ & 0.046 & $0.489 * * *$ & 0.051 & $0.502 * * *$ & 0.052 \\
\hline & Change in proportion of visible minorities kNN 800 & $-1.075 * * *$ & 0.156 & -0.027 & 0.160 & -0.056 & 0.161 \\
\hline & Proportion of visible minorities among kNN 51200 & 0.152 & 0.090 & $0.279 * *$ & 0.098 & $0.367^{* * *}$ & 0.099 \\
\hline \multicolumn{8}{|l|}{ Parents } \\
\hline & Proportion of visible minorities among kNN 800 & $2.006 * * *$ & 0.052 & $1.615 * * *$ & 0.062 & $1.555^{* * *}$ & 0.063 \\
\hline & Change in proportion of visible minorities kNN 800 & $-2.601 * * *$ & 0.226 & $0.973 * * *$ & 0.230 & $1.005 * * *$ & 0.232 \\
\hline & Proportion of visible minorities among kNN 51200 & $-0.674 * * *$ & 0.110 & $-1.134 * * *$ & 0.123 & $-0.993 * * *$ & 0.126 \\
\hline \multicolumn{2}{|c|}{ Controls for SES neighborhood variables } & \multicolumn{2}{|l|}{ No } & \multicolumn{2}{|c|}{ Yes } & \multicolumn{2}{|l|}{ Yes } \\
\hline \multicolumn{2}{|c|}{ Controls for individual variables } & \multicolumn{2}{|l|}{ No } & \multicolumn{2}{|l|}{ No } & \multicolumn{2}{|l|}{ Yes } \\
\hline
\end{tabular}

Source: Own calculcations from population register data. 
List of supplementary materials for PSP manuscript \#0019-0022

\section{\# Title}

Supplementary tables 1 Descriptives for neighbourhoods at 25 th and 75 th percentile concentration of visible minorities

2 Dissimilarity index for the Copenhagen area 2003-2014

3.1 Complete results from three models of out-migration among the full population

3.2 Complete results from three models of out-migration among the natives population

3.3 Complete results from three models of out-migration among the descendants population

4.1 Complete results from three models of flight

4.2 Complete results from three models of flight among natives

4.3 Complete results from three models of flight among descendants

5.1 Complete results from three models of out-migration among native parents

5.2 Complete results from three models of out-migration among native childless

6.1 Main results from models of out-migration using three definitions of minorities

Supplementary figures

1 Proportion of visible minorities in grid cells in the Copenhagen metropolitan area. 2014.

2 Proportion of visible minorities in individualized neighbourhoods $(\mathrm{k}=800)$ in Copenhagen. 2014.

3 Change in \% of visible minorities in individualized neighbourhoods ( $k=800$ ) in Copenhagen. 2003-2014.

Source for all tables: Own calculcations from population register data. 
TABLE S1. DESCRIPTIVE STATISTICS BELOW 25TH AND ABOVE 75TH PERCENTILE ON PROPORTION OF VISIBLE MINORITIES

\begin{tabular}{|c|c|c|c|c|c|c|}
\hline Variable & Definition/category & & 25th perce & & Above 75th per & \\
\hline & & $m$ & $s$ & & $m$ & \\
\hline Out-migration & Moved to new grid cell & & 0.100 & 0.301 & 0.127 & 0.333 \\
\hline Flight & Moved to with lower \% minorities & & 0.023 & 0.151 & 0.094 & 0.291 \\
\hline Migration status & Native & & 0.903 & 0.297 & 0.686 & 0.464 \\
\hline & Immigrant & & 0.091 & 0.288 & 0.290 & 0.454 \\
\hline & Descendant of immigrants & & 0.006 & 0.079 & 0.025 & 0.156 \\
\hline Minority status & Visible minority & & 0.029 & 0.167 & 0.226 & 0.418 \\
\hline & Non-Western & & 0.035 & 0.184 & 0.258 & 0.438 \\
\hline & Muslim Country & & 0.010 & 0.100 & 0.160 & 0.367 \\
\hline Sex & Male & & 0.476 & 0.499 & 0.488 & 0.500 \\
\hline & Female & & 0.524 & & 0.512 & \\
\hline Age & $25-44$ & & 0.422 & 0.494 & 0.492 & 0.500 \\
\hline & $45-64$ & & 0.363 & 0.481 & 0.320 & 0.466 \\
\hline & $65+$ & & 0.214 & 0.410 & 0.188 & 0.391 \\
\hline Education & Low: Primary/lower secondary & & 0.149 & 0.356 & 0.323 & 0.468 \\
\hline & Medium: Completed secondary & & 0.354 & 0.478 & 0.397 & 0.489 \\
\hline & High: Tertiary education & & 0.497 & 0.500 & 0.273 & 0.445 \\
\hline No. of children & Childless & & 0.644 & 0.479 & 0.677 & 0.467 \\
\hline & 1-2 children & & 0.311 & 0.463 & 0.256 & 0.437 \\
\hline & 3 or more children & & 0.045 & 0.207 & 0.066 & 0.249 \\
\hline Union status & Single & & 0.356 & 0.479 & 0.497 & 0.500 \\
\hline & Married or cohabiting & & 0.644 & & 0.503 & \\
\hline Labour market & Not currently employed & & 0.066 & 0.249 & 0.153 & 0.360 \\
\hline & Currently employed & & 0.934 & & 0.847 & \\
\hline Sample size (exclu & all missing values) & & 629884 & $(600068)$ & 629289 & 79203) \\
\hline
\end{tabular}

Source: Own calculcations from population register data. 
TABLE S2. DISSIMILARITY INDICES FOR COPENHAGEN AREA USING GRID CELLS AND KNN METHOD. 2003-2014.

\begin{tabular}{lrr} 
Year & kNN 800 & \multicolumn{1}{c}{ Grid cells } \\
2003 & 0.439 & 0.557 \\
2007 & 0.420 & 0.535 \\
2011 & 0.399 & 0.509 \\
2014 & 0.395 & 0.503
\end{tabular}

Source: Own calculcations from population register data. 
TABLE S3.1. ESTIMATES FROM MODELS OF OUT-MIGRATION ON FULL POPULATION. LOGIT COEFFICIENTS.

\section{Variable}

Proportion of visible minorities among kNN 800

Change in proportion of visible minorities kNN 800

Proportion of visible minorities among kNN 51200

Proportion of individuals with high education kNN 800

Proportion of individuals with high incomes kNN 800

Sex

$\begin{array}{ll} & \text { Male } \\ \text { Age } & 25-44 \\ & 45-64 \\ & 65+\end{array}$

Education

Low educ

Medium education

High education

No. of children

None

1-2 children

$3+$ children

Married or cohabiting

Yes

No

Employed

Yes

No

Secular trend

2003

2007

2011

Intercept

Wald $\mathrm{Chi}^{2}$

df

Pseudo $\mathrm{R}^{2}$

$N$ persons
Model 1

$b$

\begin{tabular}{ll}
\multicolumn{2}{c}{$S E$} \\
$1.137 * * *$ & 0.026 \\
$-4.431 * * *$ & 0.109 \\
-0.026 & 0.054
\end{tabular}

Model 2

Model 3

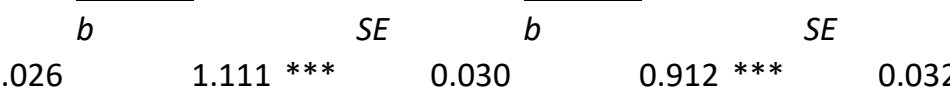

$\begin{array}{llll}-0.372 * * * & 0.061 & -0.303 * * * & 0.064\end{array}$

$2.958 * * * \quad 0.022 \quad 1.350 * * * \quad 0.025$

$-5.286 * * * \quad 0.043 \quad-2.172 * * * \quad 0.046$

0.000

$0.023 * * * \quad 0.005$

$1.745 * * * \quad 0.009$

$0.463 * * * \quad 0.010$

0.000

0.000

$0.010 \quad 0.007$

$0.097^{* * *} \quad 0.008$

0.000

$-0.288 * * * \quad 0.006$

$-0.698 * * * \quad 0.016$

0.000

$0.182 * * * \quad 0.006$

0.143

$0.000 \quad 0.008$

$0.018 * * \quad 0.006$

$0.082 * * * \quad 0.006$

\begin{tabular}{|c|c|c|c|c|}
\hline$-2.203 * * *$ & 0.006 & $-2.700 * * *$ & 0.014 & $-3.667 * * *$ \\
\hline 1161.81 & & 5318.57 & & 5711.54 \\
\hline 3 & & 5 & & 16 \\
\hline 0.002 & & 0.014 & & 0.054 \\
\hline 2056613 & & 2052984 & & 2007497 \\
\hline
\end{tabular}


TABLE S3.2. ESTIMATES FROM MODELS OF OUT-MIGRATION ON NATIVES ONLY. LOGIT COEFFICIENTS.

\section{Variable}

Proportion of visible minorities among kNN 800

Change in proportion of visible minorities kNN 800

Proportion of visible minorities among kNN 51200

Proportion of individuals with high education kNN 800

Proportion of individuals with high incomes kNN 800

Sex

Female

Male

Age

25-44

45-64

$65+$

Education Low educ

Medium education

High education

No. of children

None

1-2 children

$3+$ children

Married or cohabiting

Yes

No

Employed

Yes

No

Secular trend

2003

2007

2011

Intercept

Wald $\mathrm{Chi}^{2}$

df

Pseudo $\mathrm{R}^{2}$

$\mathrm{N}$ persons

\begin{tabular}{|c|c|c|c|c|c|}
\hline \multicolumn{2}{|l|}{ Model 1} & \multicolumn{2}{|l|}{ Model 2} & \multicolumn{2}{|l|}{ Model 3} \\
\hline$S E$ & & $b$ & & $b$ & \\
\hline $1.114 * * *$ & 0.027 & $1.068 * * *$ & 0.031 & $3.320 * * *$ & 0.035 \\
\hline$-4.500 * * *$ & 0.111 & $-0.497 * * *$ & 0.112 & $1.529 * * *$ & 0.133 \\
\hline-0.037 & 0.055 & $-0.390 * * *$ & 0.062 & $-0.890 * * *$ & 0.083 \\
\hline & & $2.990 * * *$ & 0.023 & $1.370 * * *$ & 0.026 \\
\hline & & $-5.333 * * *$ & 0.044 & $-2.194 * * *$ & 0.047 \\
\hline & & & & 0.000 & \\
\hline & & & & $0.023 * * *$ & 0.005 \\
\hline & & & & $1.7432 * * *$ & 0.010 \\
\hline & & & & $0.461 * * *$ & 0.010 \\
\hline & & & & 0.000 & \\
\hline & & & & 0.000 & \\
\hline & & & & 0.008 & 0.008 \\
\hline & & & & $0.094 * * *$ & 0.008 \\
\hline & & & & 0.000 & \\
\hline & & & & $-0.284 * * *$ & 0.006 \\
\hline & & & & $-0.685 * * *$ & 0.016 \\
\hline & & & & 0.000 & \\
\hline & & & & $0.182 * * *$ & 0.006 \\
\hline & & & & 0.000 & \\
\hline & & & & $0.148 * * *$ & 0.008 \\
\hline & & & & $0.015 *$ & 0.006 \\
\hline & & & & $-0.084 * * *$ & 0.006 \\
\hline$-2.208 * * *$ & 0.006 & $-2.796 * * *$ & 0.014 & $-3.409 * * *$ & 0.013 \\
\hline 6748.940 & & 6125.340 & & 3882.810 & \\
\hline 3 & & 5 & & 16 & \\
\hline 0.008 & & 0.015 & & 0.037 & \\
\hline 2024519 & & 2020897 & & 1977013 & \\
\hline
\end{tabular}


TABLE S3.3. ESTIMATES FROM MODELS OF OUT-MIGRATION ON DESCENDANTS ONLY. LOGIT COEFFICIENTS.

\section{Variable}

Proportion of visible minorities among kNN 800

Change in proportion of visible minorities kNN 800

Proportion of visible minorities among kNN 51200

Proportion of individuals with high education kNN 800

Proportion of individuals with high incomes kNN 800

Sex

$$
\begin{aligned}
& \text { Female } \\
& \text { Male }
\end{aligned}
$$

Age

25-44

45-64

$65+$

Education

Low educ

Medium education

High education

No. of children

None

1-2 children

$3+$ children

Married or cohabiting

Yes

No

Employed

Yes

No

2003

Secular trend

2007

2011

Intercept

Wald $\mathrm{Chi}^{2}$

df

Pseudo $\mathrm{R}^{2}$

$\mathrm{N}$ persons
Model 1

$b$

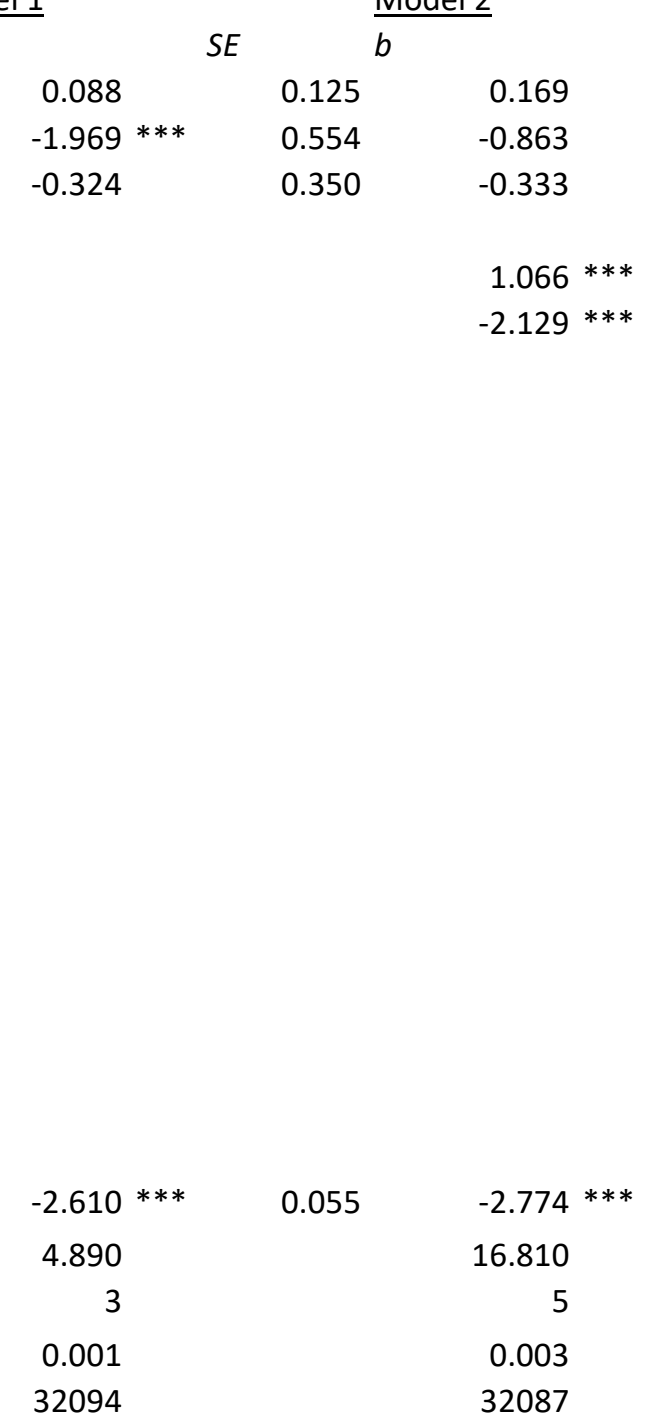

\begin{tabular}{|c|}
\hline 0.145 \\
\hline 0.567 \\
\hline
\end{tabular}

Model 3

SE

$0.367-0.056$

0.595

0.391

0.151

$0.516 * * \quad 0.165$

0.314

0.339

0.000

$-0.002$

$2.133 * * * \quad 0.246$

$0.905 * * * \quad 0.255$

0.000

0.000

0.031

$0.182 * * * \quad 0.042$

0.000

$-0.421 * * * \quad 0.043$

$-0.938 * * * \quad 0.080$

0.000

$0.130 * * * \quad 0.039$

0.000

0.065

0.000

$0.170 * * * \quad 0.041$

$-0.037$

$-3.800 * * * \quad 0.264$

43.300

16

0.029

30484 
TABLE S4.1. ESTIMATES FROM MODELS OF FLIGHT ON FULL POPULATION. LOGIT COEFFICIENTS.

\section{Variable}

Proportion of visible minorities among kNN 800

Change in proportion of visible minorities kNN 800

Proportion of visible minorities among kNN 51200

Proportion of individuals with high education kNN 800

Proportion of individuals with high incomes kNN 800

Sex

Age

Female

Male

25-44

45-64

$65+$

Education

Low educ

Medium education

High education

No. of children

None

1-2 children

$3+$ children

Married or cohabiting

No

Employed

Yes

No

2003

Secular trend

2007

2011

Intercept

Wald $\mathrm{Chi}^{2}$

df

Pseudo $\mathrm{R}^{2}$

$\mathrm{N}$ persons
Model 1

b

\begin{tabular}{rr}
\multicolumn{2}{r}{$S E$} \\
$3.358 * * *$ & 0.028 \\
$-2.345 * * *$ & 0.131 \\
0.030 & 0.070
\end{tabular}

Model 2

Model 3

\begin{tabular}{|c|c|c|c|}
\hline \multicolumn{2}{|c|}{$S E$} & \multicolumn{2}{|c|}{$S E$} \\
\hline $3.140 * * *$ & 0.033 & $3.189 * * *$ & 0.034 \\
\hline $0.796 * * *$ & 0.128 & $1.561 * * *$ & 0.131 \\
\hline$-0.779 * * *$ & 0.079 & $-0.939 * * *$ & 0.082 \\
\hline $2.664 * * *$ & 0.028 & $1.137 * * *$ & 0.032 \\
\hline \multirow[t]{19}{*}{$-6.161 * * *$} & 0.061 & $-3.547 * * *$ & 0.066 \\
\hline & & 0.000 & \\
\hline & & $0.013 *$ & 0.006 \\
\hline & & $1.658 * * *$ & 0.013 \\
\hline & & $0.460 * * *$ & 0.014 \\
\hline & & 0.000 & \\
\hline & & 0.000 & \\
\hline & & $0.088 * * *$ & 0.009 \\
\hline & & $0.237 * * *$ & 0.010 \\
\hline & & 0.000 & \\
\hline & & $-0.199 * * *$ & 0.008 \\
\hline & & $-0.658 * * *$ & 0.021 \\
\hline & & 0.000 & \\
\hline & & $0.048 * * *$ & 0.007 \\
\hline & & 0.000 & \\
\hline & & $0.020 *$ & 0.010 \\
\hline & & 0.000 & \\
\hline & & $0.031 * * *$ & 0.008 \\
\hline & & $-0.082 * * *$ & 0.008 \\
\hline$-3.431 * * *$ & 0.018 & $-4.297 * * *$ & 0.023 \\
\hline 6258.89 & & 3923.49 & \\
\hline 5 & & 16 & \\
\hline 0.015 & & 0.036 & \\
\hline 2052984 & & 2007497 & \\
\hline
\end{tabular}


TABLE S4.2. ESTIMATES FROM MODELS OF FLIGHT ON NATIVES ONLY. LOGIT COEFFICIENTS.

Variable

Proportion of visible minorities among kNN 800

Change in proportion of visible minorities kNN 800

Proportion of visible minorities among kNN 51200

Proportion of individuals with high education kNN 800

Proportion of individuals with high incomes kNN 800

Sex

Female

Male

Age

25-44

45-64

$65+$

Education Low educ

Medium education

High education

No. of children

None

1-2 children

$3+$ children

Married or cohabiting

No

Employed

Yes

No

2003

Secular trend

2007

2011

Intercept

Wald $\mathrm{Chi}^{2}$

df

Pseudo $\mathrm{R}^{2}$

$\mathrm{N}$ persons
Model 1

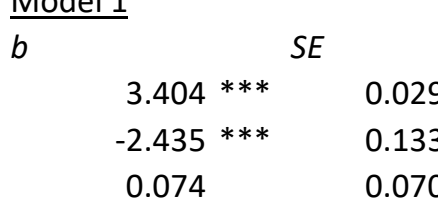

Model 2

SE Model 3

0.133

0.070

$\begin{array}{ll}3.170 * * * & 0.034 \\ 0.771 * * * & 0.131\end{array}$

$-0.738 * * * \quad 0.079$

$2.686 * * * \quad 0.029$

$-6.177 * * * \quad 0.062$

$1.125 * * * \quad 0.033$

$-3.498 * * * \quad 0.066$

0.000

$0.012 * \quad 0.006$

$1.675 * * * \quad 0.013$

$0.458 * * * \quad 0.014$

0.000

0.000

$0.078 * * * \quad 0.010$

$0.225 * * * \quad 0.010$

0.000

$-0.194 * * * \quad 0.008$

$-0.631 * * * \quad 0.021$

0.000

$0.047^{* * *} \quad 0.007$

0.000

$0.035^{* *} \quad 0.011$

0.000

$0.023 * * \quad 0.008$

$-0.088 * * * \quad 0.008$

$-4.309 * * * \quad 0.023$

$-3.139 *$
6748.940
3
0.008
2024519

0.007

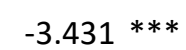

6125.340

0.015

2020897
3882.810

16

0.037

1977013 
TABLE S4.3. ESTIMATES FROM MODELS OF FLIGHT ON DESCENDANTS ONLY. LOGIT COEFFICIENTS.

\begin{tabular}{|c|c|}
\hline \multicolumn{2}{|l|}{ Variable } \\
\hline \multicolumn{2}{|c|}{ Proportion of visible minorities among kNN 80} \\
\hline \multicolumn{2}{|c|}{ Change in proportion of visible minorities kNN } \\
\hline \multicolumn{2}{|c|}{ Proportion of visible minorities among kNN 51} \\
\hline \multicolumn{2}{|c|}{ Proportion of individuals with high education $\mathrm{k}$} \\
\hline \multicolumn{2}{|c|}{ Proportion of individuals with high incomes kN } \\
\hline \multirow[t]{2}{*}{ Sex } & Female \\
\hline & Male \\
\hline \multirow[t]{3}{*}{ Age } & $25-44$ \\
\hline & $45-64$ \\
\hline & $65+$ \\
\hline \multirow[t]{3}{*}{ Education } & Low educ \\
\hline & Medium education \\
\hline & High education \\
\hline \multirow[t]{3}{*}{ No. of children } & None \\
\hline & 1-2 children \\
\hline & $3+$ children \\
\hline \multirow[t]{2}{*}{ Married or cohabiting } & Yes \\
\hline & No \\
\hline \multirow[t]{2}{*}{ Employed } & Yes \\
\hline & No \\
\hline \multirow[t]{3}{*}{ Secular trend } & 2003 \\
\hline & 2007 \\
\hline & 2011 \\
\hline \multicolumn{2}{|l|}{ Intercept } \\
\hline \multicolumn{2}{|l|}{$\begin{array}{l}\text { Wald } \mathrm{Chi}^{2} \\
\mathrm{df}\end{array}$} \\
\hline \multicolumn{2}{|l|}{ Pseudo $\mathrm{R}^{2}$} \\
\hline $\mathrm{N}$ persons & \\
\hline
\end{tabular}

\begin{tabular}{|c|c|c|c|c|c|}
\hline \multicolumn{2}{|l|}{ Model 1} & \multicolumn{2}{|c|}{ Model 2} & \multicolumn{2}{|c|}{ Model 3} \\
\hline$b$ & t & & & & \\
\hline $2.607 * * *$ & 0.149 & $2.586 * * *$ & 0.176 & $2.822 * * *$ & 0.182 \\
\hline-0.427 & 0.699 & 0.789 & 0.706 & 0.693 & 0.732 \\
\hline$-2.451 * * *$ & 0.488 & $-2.642 * * *$ & 0.519 & $-2.465 * * *$ & 0.553 \\
\hline & & $1.397 * * *$ & 0.207 & $1.016 * * *$ & 0.226 \\
\hline & & $-3.756 * * *$ & 0.488 & $-2.865 * * *$ & 0.533 \\
\hline & & & & 0.000 & \\
\hline & & & & 0.041 & 0.045 \\
\hline & & & & $1.745 * * *$ & 0.341 \\
\hline & & & & $1.138 * *$ & 0.353 \\
\hline & & & & 0.000 & \\
\hline & & & & 0.000 & \\
\hline & & & & $0.195 * * *$ & 0.057 \\
\hline & & & & $0.380 * * *$ & 0.058 \\
\hline & & & & 0.000 & \\
\hline & & & & $-0.317 * * *$ & 0.058 \\
\hline & & & & $-0.851 * * *$ & 0.108 \\
\hline & & & & 0.000 & \\
\hline & & & & 0.070 & 0.052 \\
\hline & & & & 0.000 & \\
\hline & & & & -0.051 & 0.053 \\
\hline & & & & 0.000 & \\
\hline & & & & $0.166 * *$ & 0.057 \\
\hline & & & & -0.012 & 0.050 \\
\hline$-2.610 * * *$ & 0.055 & $-2.774 * * *$ & 0.122 & $-4.604 * * *$ & 0.365 \\
\hline 126.27 & & 86.05 & & 38.40 & \\
\hline 3 & & 5 & & 16 & \\
\hline 0.010 & & 0.013 & & 0.022 & \\
\hline 32094 & & 32087 & & 30484 & \\
\hline
\end{tabular}


TABLE S5.1. ESTIMATES FROM MODELS OF OUT-MIGRATION AMONG CHILDLESS NATIVES. LOGIT COEFFICIENTS.

\section{Variable}

Proportion of visible minorities among kNN 800

Change in proportion of visible minorities kNN 800

Proportion of visible minorities among kNN 51200

Proportion of individuals with high education kNN 800

Proportion of individuals with high incomes kNN 800

\begin{tabular}{|c|c|}
\hline \multirow[t]{2}{*}{ Sex } & Female \\
\hline & Male \\
\hline \multirow[t]{3}{*}{ Education } & Low educ \\
\hline & Medium education \\
\hline & High education \\
\hline \multirow[t]{2}{*}{ Married or cohabiting } & Yes \\
\hline & No \\
\hline \multirow[t]{2}{*}{ Employed } & Yes \\
\hline & No \\
\hline \multirow[t]{3}{*}{ Secular trend } & 2003 \\
\hline & 2007 \\
\hline & 2011 \\
\hline \multicolumn{2}{|l|}{ Intercept } \\
\hline \multicolumn{2}{|l|}{ Wald $\mathrm{Chi}^{2}$} \\
\hline \multicolumn{2}{|l|}{ df } \\
\hline \multicolumn{2}{|l|}{ Pseudo $\mathrm{R}^{2}$} \\
\hline $\mathrm{N}$ persons & \\
\hline
\end{tabular}

Model 1

$b$

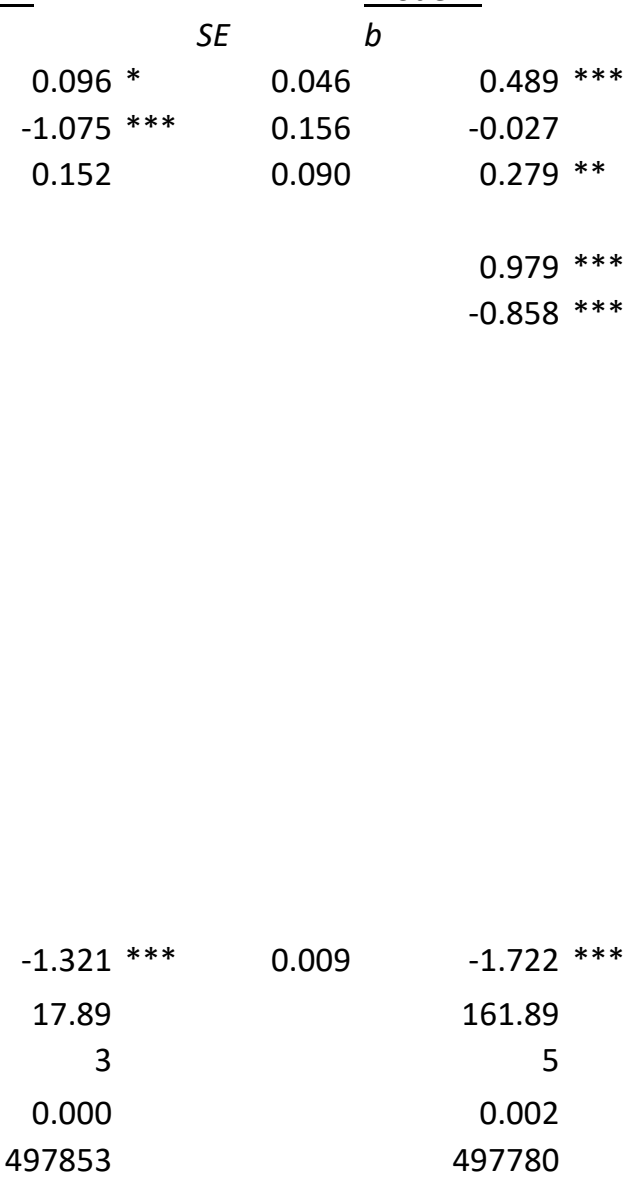

Model 3

\begin{tabular}{lll}
\multicolumn{1}{c}{$b$} & $S E$ \\
0.051 & $0.502 * * *$ & 0.052 \\
0.160 & -0.056 & 0.161 \\
0.098 & $0.367 * * *$ & 0.099 \\
& & \\
0.036 & $0.802 * * *$ & 0.039
\end{tabular}

$0.074 \quad-0.720 * * * \quad 0.075$

\begin{tabular}{|c|c|c|}
\hline \multicolumn{2}{|r|}{$-0.062 * * *$} & 0.007 \\
\hline & $0.110 * * *$ & 0.012 \\
\hline & $0.232 * * *$ & 0.012 \\
\hline & $0.050 * * *$ & 0.008 \\
\hline & $0.112 * * *$ & 0.011 \\
\hline & $0.063 * * *$ & 0.009 \\
\hline & $-0.088 * * *$ & 0.009 \\
\hline 0.022 & $-1.838 * * *$ & 0.027 \\
\hline & 142.88 & \\
\hline & 12 & \\
\hline & 0.004 & \\
\hline & 21.000 & \\
\hline
\end{tabular}

Source: Own calculcations from population register data. 
TABLE S5.2. ESTIMATES FROM MODELS OF OUT-MIGRATION AMONG PARENT NATIVES. LOGIT COEFFICIENTS.

Variable

Proportion of visible minorities among kNN 800

Change in proportion of visible minorities kNN 800

Proportion of visible minorities among kNN 51200

Proportion of individuals with high education kNN 800

Proportion of individuals with high incomes kNN 800

\begin{tabular}{|c|c|}
\hline \multirow[t]{2}{*}{ Sex } & Female \\
\hline & Male \\
\hline \multirow[t]{3}{*}{ Education } & Low educ \\
\hline & Medium education \\
\hline & High education \\
\hline \multirow[t]{2}{*}{ Married or cohabiting } & Yes \\
\hline & No \\
\hline \multirow[t]{2}{*}{ Employed } & Yes \\
\hline & No \\
\hline \multirow[t]{3}{*}{ Secular trend } & 2003 \\
\hline & 2007 \\
\hline & 2011 \\
\hline \multicolumn{2}{|l|}{ Intercept } \\
\hline \multicolumn{2}{|l|}{$\begin{array}{l}\text { Wald } \mathrm{Chi}^{2} \\
\mathrm{df}\end{array}$} \\
\hline \multicolumn{2}{|l|}{ Pseudo $\mathrm{R}^{2}$} \\
\hline $\mathrm{N}$ persons & \\
\hline
\end{tabular}

\begin{tabular}{|c|c|c|c|c|c|}
\hline Model 1 & & Model 2 & & Model 3 & \\
\hline$b$ & & $b$ & & $b$ & \\
\hline $2.006 * * *$ & 0.052 & $1.615 * * *$ & 0.062 & $1.555 * * *$ & 0.063 \\
\hline$-2.601 * * *$ & 0.226 & $0.973 * * *$ & 0.230 & $1.005 * * *$ & 0.232 \\
\hline$-0.674 * * *$ & 0.110 & $-1.134 * * *$ & 0.123 & $-0.993 * * *$ & 0.126 \\
\hline & & $2.506 * * *$ & 0.044 & $2.457 * * *$ & 0.048 \\
\hline & & $-5.228 * * *$ & 0.084 & $-5.137 * * *$ & 0.086 \\
\hline & & & & $0.108 * * *$ & 0.010 \\
\hline & & & & $-0.062 * * *$ & 0.017 \\
\hline & & & & 0.025 & 0.017 \\
\hline & & & & $0.078 * * *$ & 0.014 \\
\hline & & & & $0.165 * * *$ & 0.016 \\
\hline & & & & $0.059 * * *$ & 0.012 \\
\hline & & & & $-0.065 * * *$ & 0.011 \\
\hline$-2.024 * * *$ & 0.011 & $-2.328 * * *$ & 0.027 & $-2.395 * * *$ & 0.034 \\
\hline 549.47 & & 1329.53 & & 587.09 & \\
\hline 3 & & 5 & & 12 & \\
\hline 0.003 & & 0.016 & & 0.017 & \\
\hline 425076 & & 425039 & & 423332.000 & \\
\hline
\end{tabular}

Source: Own calculcations from population register data. 
TABLE S6.1. MAIN RESULTS ON NEIGHBORHOOD COMPOSITION FROM MODELS OF OUT-MIGRATION USING THREE DEFINITIONS OF MINORITIES

\section{Variable Population}

Proportion of visible minorities among kNN 800

$$
\text { Full }
$$

Natives

Descendants

Controls for SES neighborhood variables

Controls for individual variables

Source: Own calculcations from population register data.

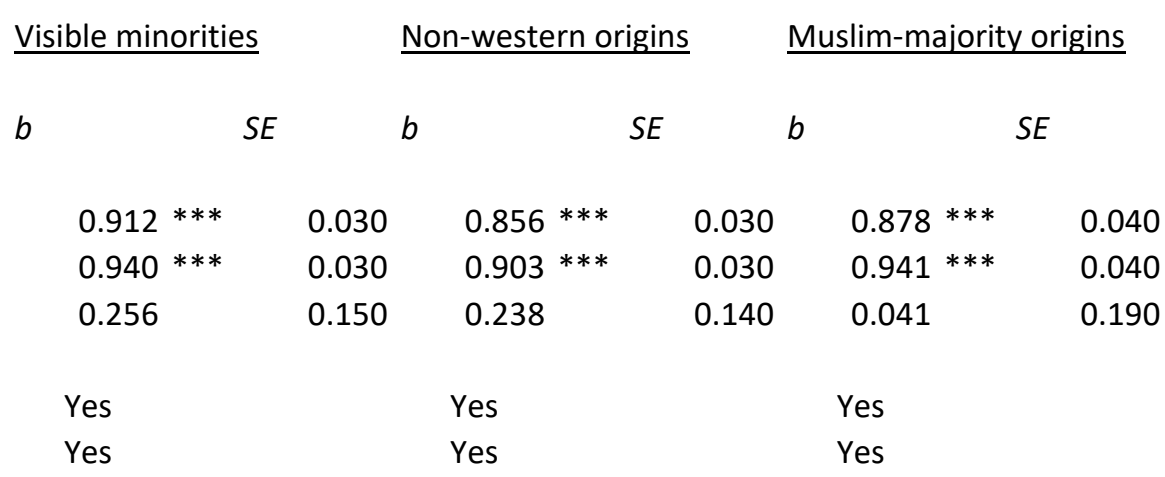


Figure S1. Proportion of visible minorities in grid cells in the Copenhagen metropolitan area in 2014.

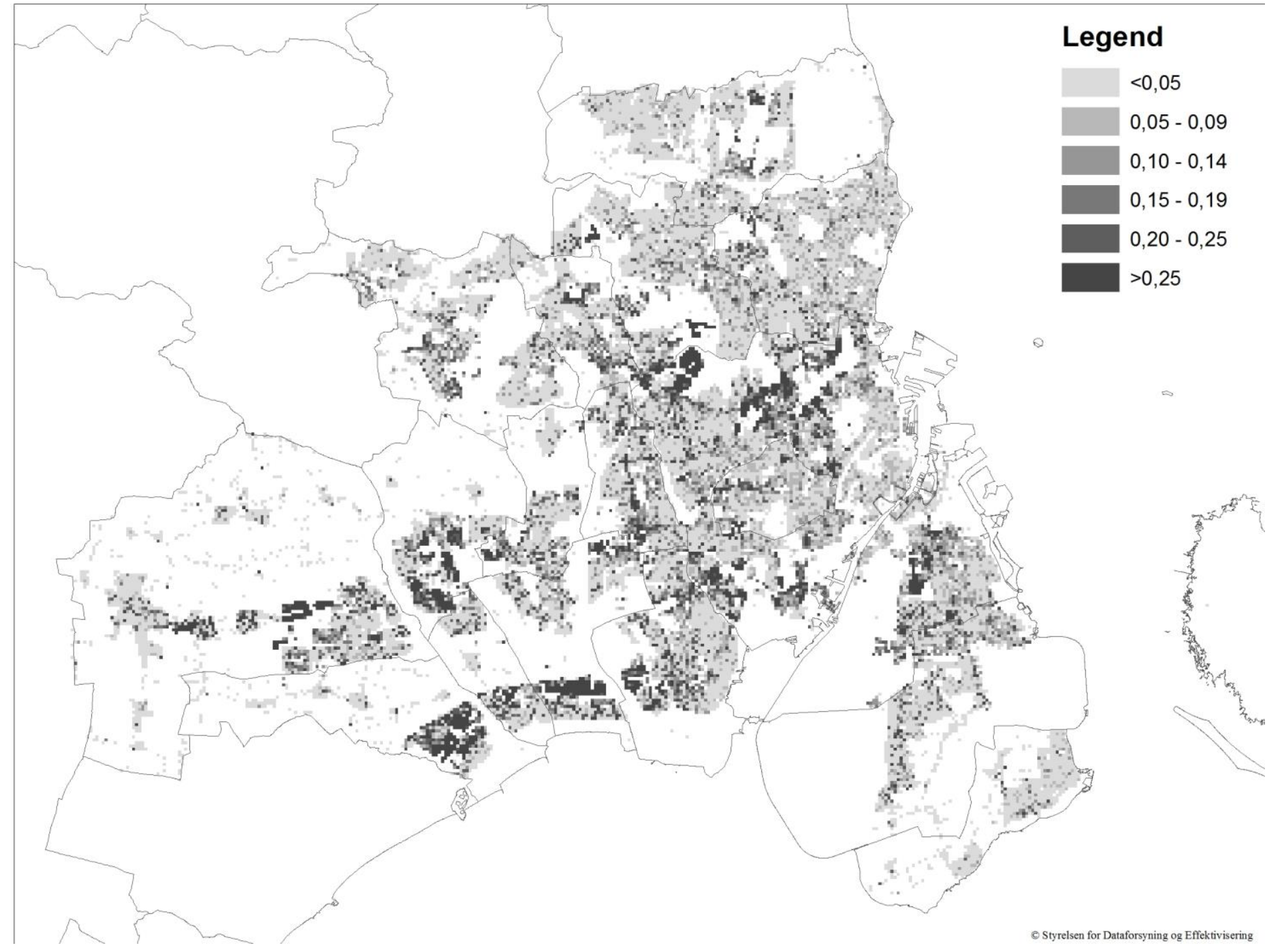


Figure S2. Proportion of visible minorities in individualized neighborhoods $(\mathrm{k}=800)$ in the Copenhagen metropolitan area in 2014.

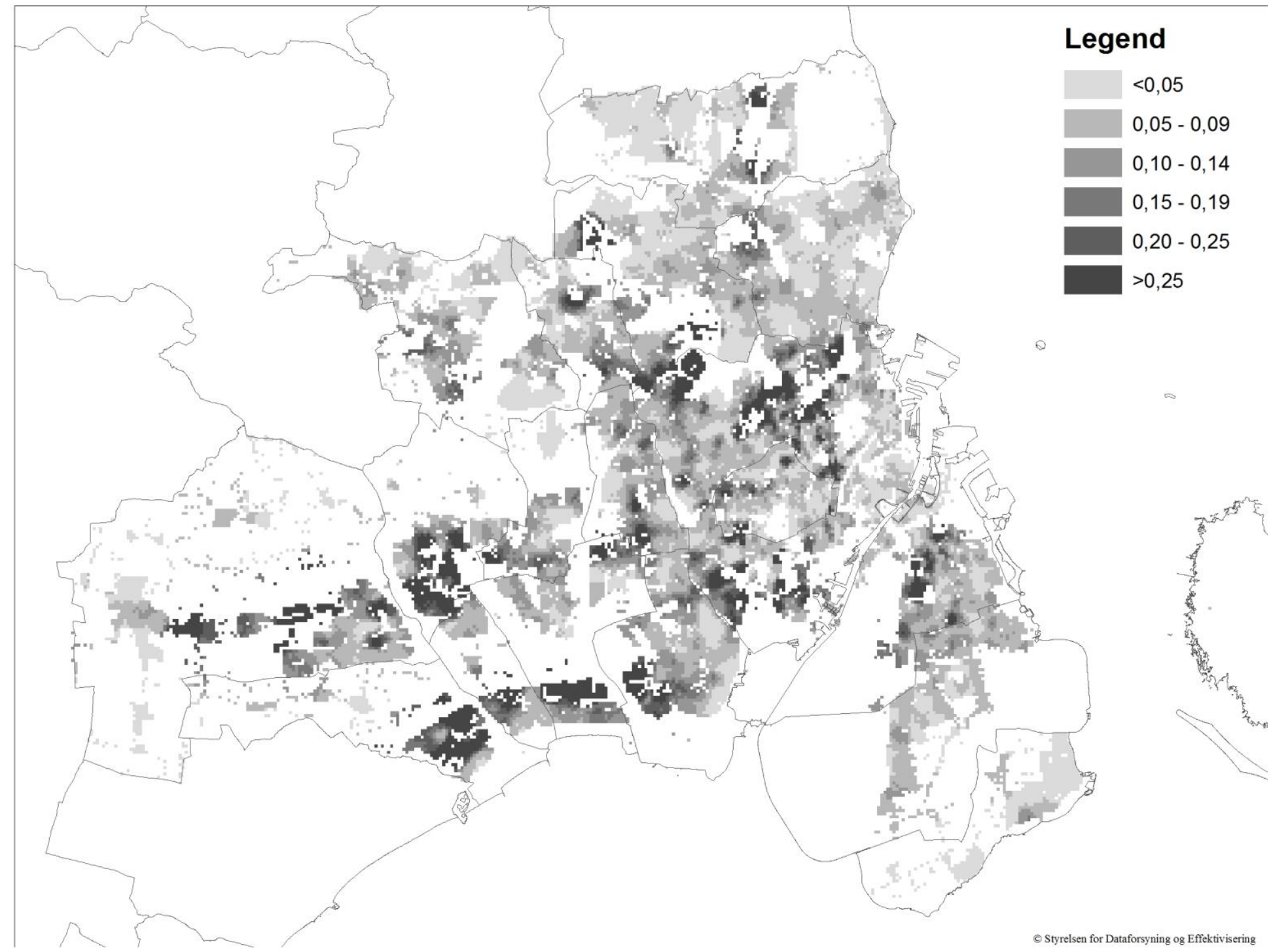


Figure S3. Change from 2003 to 2014 in the share of visible minorities in individualized neighborhoods (k=800) in the Copenhagen metropolitan area.

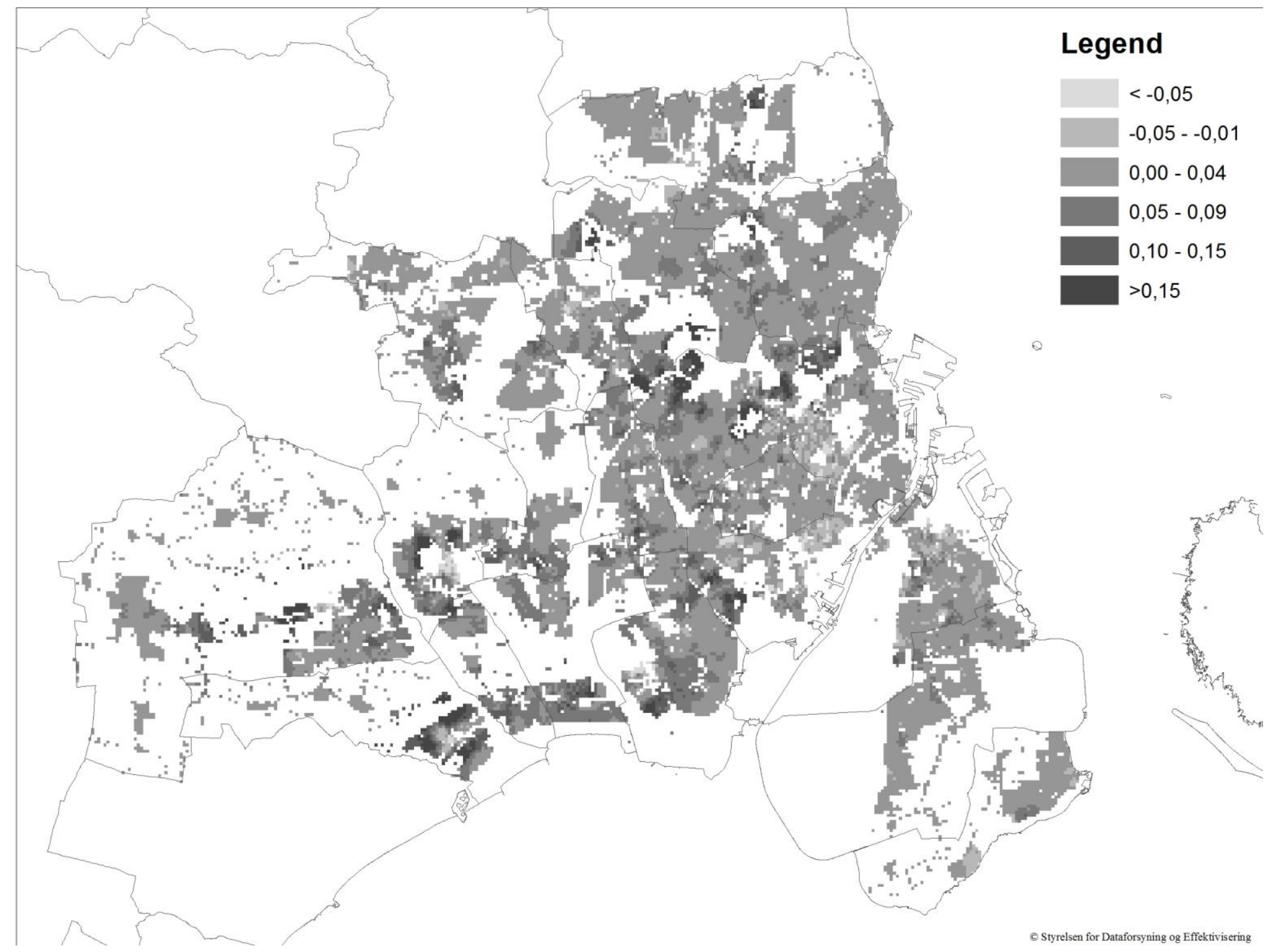

